\title{
The Missing Link in Early Emotional Processing
}

\author{
Luis Carretié \\ Facultad de Psicología, Universidad Autónoma de Madrid, Spain \\ Raghunandan K. Yadav \\ School of Life Sciences, Jawaharlal Nehru University, India \\ Constantino Méndez-Bértolo \\ Instituto de Investigación Biomédica de Cádiz, Spain
}

\begin{abstract}
Initial evaluation structures (IESs) currently proposed as the earliest detectors of affective stimuli (e.g., amygdala, orbitofrontal cortex, or insula) are high-order structures (a) whose response latency cannot account for the first visual cortex emotion-related response $(\sim 80 \mathrm{~ms})$, and (b) lack the necessary infrastructure to locally analyze the visual features that define emotional stimuli. Several thalamic structures accomplish both criteria. The lateral geniculate nucleus (LGN), a first-order thalamic nucleus that actively processes visual information, with the complement of the thalamic reticular nucleus (TRN) are proposed as core IESs. This LGN-TRN tandem could be supported by the pulvinar, a second-order thalamic structure, and by other extrathalamic nuclei. The visual thalamus, scarcely explored in affective neurosciences, seems crucial in early emotional evaluation.
\end{abstract}

\section{Keywords}

emotion, initial evaluation, lateral geniculate nucleus, pulvinar, superior colliculus, thalamic reticular nucleus, visual thalamus

\section{Introduction}

In certain and relatively frequent situations, the capability to rapidly evaluate and respond to salient stimuli, such as the abrupt onset or sudden approach of a dangerous animal or hazardous object, is crucial for survival. These and other salient stimuli cause, by definition, emotional reactions that manifest at the physiological, subjective, and/or behavioral level. The term "emotional" will be employed hereafter to refer to salient stimuli as well as their inherent multilevel consequences (Carretié, 2014; but see different and more specific definitions of "emotion" and "emotional" from diverse theoretical frames in Brosch et al., 2010). Regarding the behavioral level, each tenth of a second may be critical. Indeed, motor reactions clearly revealing a previous discrimination of emotional from nonemotional stimuli may occur between four and five tenths of a second in those tasks especially designed to favor rapid responses (e.g., Zhang \& Lu, 2012). Evidently, this emotional motor reaction is preceded by emotional neural processing, which should also be rapid.
This theoretical review and proposal focuses on this rapid neural processing of affective stimuli, and particularly on the brain structures responsible for monitoring, evaluating, and labeling visual inputs as "emotional" quickly enough to explain our fast, sometimes urgent capability to cope with some of them. Several proposals exist for these initial evaluation structures (IES), the most recurrent and noteworthy being the amygdala (e.g., for reviews or meta-analyses, see Adolphs, 2008; Costafreda et al., 2008; Ohman, 2002; Zald, 2003) due to the direct inputs it receives from the thalamus, a sort of shortcut that theoretically facilitates rapid evaluation, an issue that will be discussed later. Mainly in human and nonhuman primates, the ventral prefrontal — or orbitofrontal — cortex (vPFC) and insula have also been proposed as emotional evaluation structures (e.g., for reviews, see Norman et al., 2011; Rudebeck \& Murray, 2014). However, these three structures present some characteristics incompatible with the role of IES. One of them is their response latency, too slow for what an initial evaluator of visual input requires, as explained later. Additionally, as also devel- 


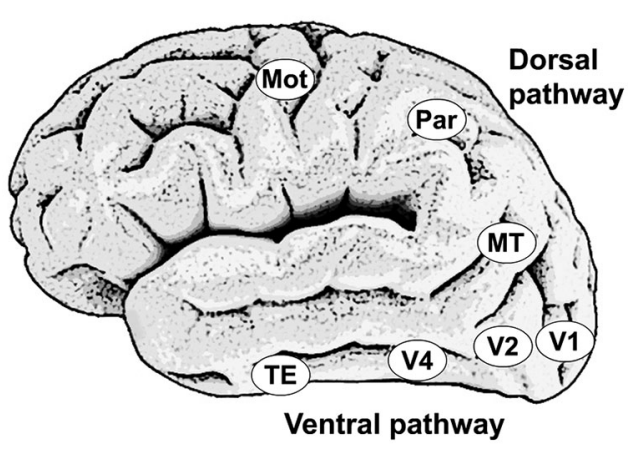

Figure 1. Schematic depiction of the main visual cortical areas and streams mentioned.

Note. Please note that $\mathrm{V} 3$ is not depicted since it is distributed in different ventral and dorsal areas (it is partly adjacent to V2 and MT).

oped in what follows, they lack the necessary, for an IES, architecture capable of rapidly recognizing certain visual features such as shapes, colors, or motion patterns that may characterize a stimulus as emotional. Therefore, IESs are still the missing link in emotional processing knowledge. However, some brain structures that have gone unnoticed by affective neuroscience in this respect meet the necessary requirements and are defended here as probable IESs.

\section{Requirements for Initial Evaluation Structures (IESs)}

As indicated, time is a critical issue regarding the definition of IESs. In this respect, event-related potentials (ERPs), the most rapid and agile brain signal that indexes neural responses to discrete stimuli, are a valuable tool. Importantly, ERPs show that emotional modulation of the visual cortex occurs in humans before $100 \mathrm{~ms}$ from stimulus onset. This is crucial since it is unanimously assumed that the visual cortex is not among the IESs, but is modulated by them (e.g., increasing its activity towards emotional stimuli). For example, $\mathrm{C} 1$, the first visual ERP component originated at the cortical level, presents increased amplitude in response to emotional visual stimuli (Acunzo et al., 2019; Eldar et al., 2010; Pourtois et al., 2004; see also Stolarova et al., 2006, reporting C1 enhanced amplitudes in response to emotionally conditioned stimuli). This component originates in V1 or striate cortex (both terms will be employed indistinctly herein) according to several studies (Capilla et al., 2016; Di Russo et al., 2003), although the contribution of the extrastriate cortex at early stages, concretely V2 and V3, cannot be discarded (Ales et al., 2010; see Figure 1). The onset of this component occurs around $50 \mathrm{~ms}$ from stimulus onset (e.g., Di Russo et al., 2003), its peak being produced as early as $63 \mathrm{~ms}$ in response to certain spatial locations (e.g., Capilla et al., 2016), and in any case before $100 \mathrm{~ms}$ (Rauss et al., 2011). This is compatible with intracranial recordings in human patients in which the V1/V2 response to visual stimuli is recorded at $60 \mathrm{~ms}$ (Krolak-Salmon et al., 2003). Importantly, the emotional modulation of $\mathrm{C} 1$ is produced between 60 and $100 \mathrm{~ms}$, peaking at $80 \mathrm{~ms}$ (Acunzo et al., 2019; Eldar et al.,
2010; Pourtois et al., 2004; Stolarova et al., 2006; see also Pizzagalli et al., 1999).

All structures currently proposed as IESs (the most recurrent being the amygdala, but also the vPFC and insula, as mentioned) have in common their mutual direct interconnections, as well as receiving early visual inputs and sending direct efferences to the visual cortex so they may indeed modulate its activity through attentional changes (for a review on the connectivity of these structures, see Carretié et al., 2009). However, if visual cortices show emotional modulation at $80 \mathrm{~ms}$ approximately (or maybe $\sim 10$ or $15 \mathrm{~ms}$ earlier, since $80 \mathrm{~ms}$ is the peak differentiation), these evaluative structures should previously present a distinctive activity for emotional stimuli (with respect to neutral). Moreover, this activity should occur with enough time to transmit their information to visual cortices prior to $80 \mathrm{~ms}$. Human intracranial recordings of evaluation structures accumulated up to now are not compatible with this prerequisite. Thus, the shortest responses sensitive to the emotional content of visual stimulation have been reported at $74 \mathrm{~ms}$ in the case of the human amygdala, and only for faces; responses to other emotional visual stimuli were produced beyond $150 \mathrm{~ms}$ (Méndez-Bértolo et al., 2016). With regard to the other two structures mentioned before, the earliest reported emotion-related activations were produced at over $80 \mathrm{~ms}: 120 \mathrm{~ms}$ in the case of vPFC (for both faces and scenes; Adolphs et al., 2006), and $140 \mathrm{~ms}$ in the case of the insula (only faces have been explored, to the best of our knowledge; Willenbockel et al., 2012). May information from the amygdala, the fastest of these structures according to current data, reach V1 before $80 \mathrm{~ms}$ from stimulus onset? Taking into account the average conduction velocity in the cerebral middlerange neurons in humans, information from the amygdala should take over $20 \mathrm{~ms}$ to reach V1 or V2 (see Table 1). The probability that the other proposed evaluation structures, such as vPFC and insula (e.g., K. H. Lee \& Siegle, 2009), may act as IES and cause the emotional V1 peak response observed at 80 $\mathrm{ms}$ is even more remote (see Table 1). In sum, and considering the available data, evaluative structures proposed thus far cannot be responsible for the early emotion effect observed in V1.

The second characteristic necessary for an IES is an architecture able to constantly monitor, evaluate, and label (if pertinent) ascending visual information. This requires an in situ processor of visual input capable of recognizing certain visual features such as shapes, colors, or motion patterns. Ultimately, this visual processing would require modules that constantly analyze the visual information transmitted by the retinal ganglion cells (i.e., those forming the optic nerve and conveying visual information to brain structures). Each module would process a specific region of the visual scene or receptive field, which is the information unit transmitted by ganglion cells. These modules could be conceptualized as a sort of focal processors in terms of the total extension of the visual field. As will be explained in following sections, these focal processing modules, which indeed exist in different parts of the brain, consist of retinotopically ${ }^{1}$ organized visual processing cells. At the same time, IESs should also be capable of global processing. Global modules would manage in parallel several focal modules to extract general information from the visual input, which often involves several focal 
Table 1. Estimated distance and transmission time between several human brain structures.

\begin{tabular}{llcr}
\hline From & To & Distance (mm) & Transmission time (ms) \\
\hline Posterior thalamus & Amygdala & 37.2 & 8.3 \\
(pulvinar/LGN) & Insula (anterior) & 72 & 16.0 \\
& Insula (posterior) & 40.8 & 9.1 \\
& VPFC (pole) & 112.8 & 25.1 \\
& VPFC (posterior) & 62.4 & 13.9 \\
V1, V2 & 86.4 & 19.2 \\
Amygdala & V1, V2 & 114 & 25.3 \\
vPFC (pole) & V1, V2 & 195.6 & 43.5 \\
vPFC (posterior) & V1, V2 & 144 & 32.0 \\
Insula (anterior extreme) & V1, V2 & 153.6 & 34.1 \\
Insula (posterior extreme) & V1, V2 & 111.6 & 24.8 \\
\hline
\end{tabular}

Note. Distances were estimated using the Big Brain tool within the Human Brain Project website (humanbrainproject.eu) and using the MNI152 template. To approach real fasciculi shape and length, we added $20 \%$ distance to the straight-line distances calculated between structures. Conduction velocity (CV) varies enormously from neuron to neuron (from less than $1 \mathrm{~m} / \mathrm{s}$ to several tens) depending on axonal diameter, myelination, arborization, or number of varicosities (Debanne, 2004), but it was computed here according to the following experimental information: (a) the CV value of $8.75 \mathrm{~m} / \mathrm{s}$ has been established per each $\mu \mathrm{m}$ of axonal diameter (Horowitz et al., 2015), (b) middle range neurons (e.g., uncinate fasciculus) are those more relevant here and present an average diameter of 0.45 to $0.61 \mu \mathrm{m}$ (Liewald et al., 2014 ), (c) the temporal gap between the human LGN and the V1 responses to the same stimulus is 20 ms (Krolak-Salmon et al., 2003). These sources of information converge in yielding an average CV of $\sim 4.5 \mathrm{~m} / \mathrm{s}$ in the type of fibers we are dealing with. Transmission times were computed using this CV.

\section{STIMULUS}

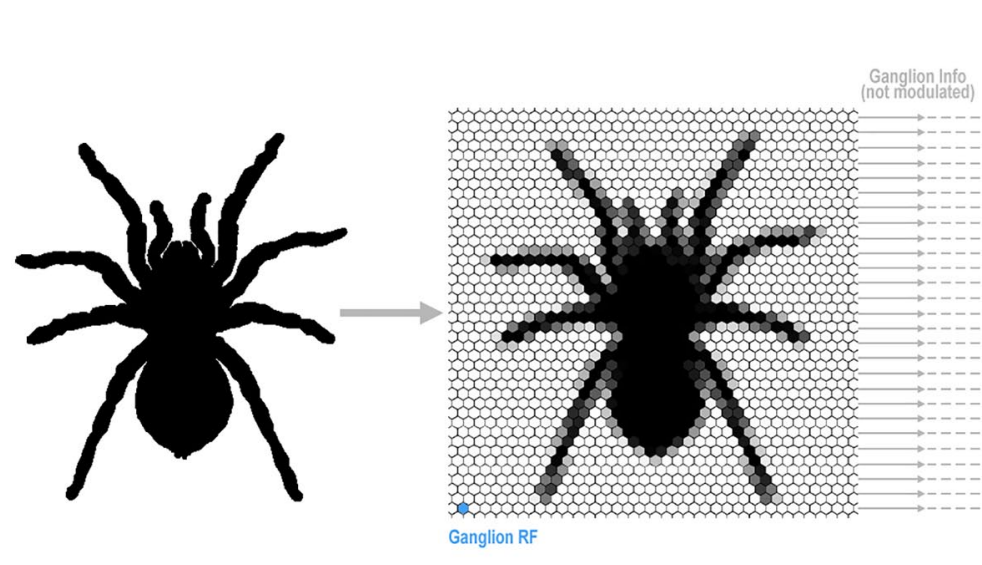

IES

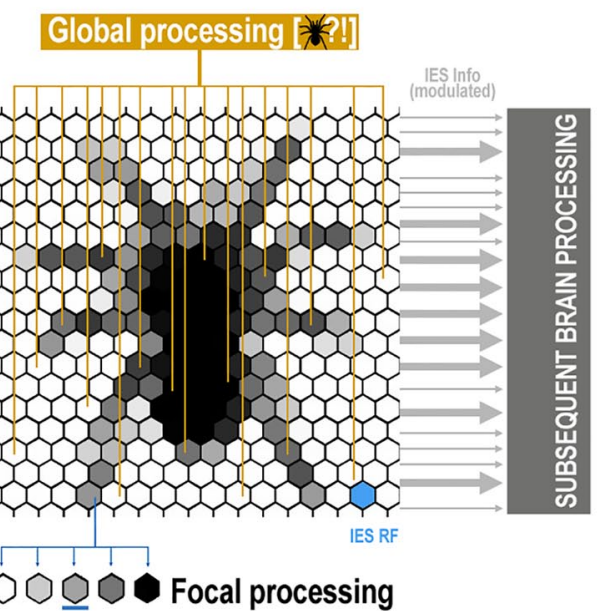

Figure 2. Schematic representation of the initial evaluation characteristics.

Note. From left to right: stimulus onset, retinal projection, and initial evaluation structure (IES). At the retina level, ganglion cells detect and transmit the visual input to a specific area: ganglion receptive field (RF). Axons of all ganglion cells, forming the optic nerve (continuous gray arrows), send this information to IESs, and may experience partial crossings or a few intermediate synapses (discontinuous gray lines). This information is not modulated by cognitive or affective factors yet. At the IES level, two types of cells are present: focal and global processors. The former are organized retinotopically but are less numerous than in the retina, so their RFs are bigger. Their activity (represented as different gray tones) depends on the visual input to its RF. Each global processor is connected to a great number of focal processors, so they manage several RFs and, hence, a big portion of the visual scene. As a function of the features they decode, they are able to modulate focal cells' output to subsequent processing areas of the brain, including V1.

receptive fields. For example, the shape of a spider that is close to us would involve several receptive fields for its legs, head, and abdomen (several focal processing modules), but the "spider shape" would require an in situ global processor that puts together the information from those individual fields (see Figure 2). These in situ processors should mark the ascending visual information if a relevant stimulus is detected, a "decision" that requires the IESs' capability of storing certain relevant visual patterns. These locally stored patterns, however, should have been defined as relevant in the past by inputs from other brain structures capable of encoding the association of stimuli with emotional consequences through learning mechanisms such as conditioning. In this latter respect, and as discussed in the final section, the amygdala and other brain regions do play a relevant role.

In sum, IES should be fast visual processors. The amygdala, vPFC, or insula have shown longer latencies than those required for an IES, as explained. Additionally, whereas the three structures 
increase their activity in response to certain visual stimuli (mainly emotional), and receive direct inputs from visual cortices, they cannot be conceptualized as visual processors. Many other brain areas also receive visual inputs and respond to them, such as the hippocampus, the anterior cingulate cortex, and the motor cortices, but they are not considered visual processors. Indeed, the infrastructure we are pointing as necessary (retinotopy, focal and global feature processing) has not been described for any of these three structures thus far. A possible explanation is that they are exclusively global processors (in the terms explained before). However, global processors require a rich interconnectivity with focal modules within retinotopic structures of the brain, as also indicated. This interconnectivity has not been described for the amygdala, the vPFC, or the insula. The fact that these structures do not meet the necessary requirements to be considered IESs does not mean they are not crucial for emotional processing. The key issue is that they receive preevaluated information (including the amygdala, the fastest responding among the three; Pessoa \& Adolphs, 2010). The most probable roles of these structures, including the aforementioned conditioning, as well as the stage within emotional processing in which they may intervene, will be discussed in the final section.

\section{The Thalamus Hypothesis}

The sensory thalamus, and particularly the visual thalamus (the part of the thalamus that processes visual information), is often conceptualized as a relay center to which sensory information arrives from the retina and from which this information is transmitted to the visual cortex and other brain areas. This role as a relay center is traditionally understood as passive, the capability of processing this information being assigned to other cerebral structures. In fact, as pointed out by Ghodrati et al. (2017), the models and representations of the visual processing route start at V1, not earlier. However, the capability of the visual thalamus to process and modulate the information it receives before transmitting it to other neural levels has been demonstrated in the cognitive field. For example, certain thalamic nuclei (described later) may filter or enhance the visual information they receive before sending it to the visual cortex as a function of attention (for reviews, see Ghodrati et al., 2017; Halassa \& Kastner, 2017; Saalmann \& Kastner, 2011; Weyand, 2016). In other words, these thalamic structures may send different signals to visual cortices in response to exactly the same stimulus depending on whether it is attended to or not. The proposal here is that this capability of the thalamus to process the information it receives may be extended to the emotional domain.

It is relevant to note that the idea of the thalamus as a structure crucial for "emotional labeling" of sensory inputs is about a century old. Cannon (1927), for example, postulated that "the peculiar quality of the emotion is added to simple sensation when the thalamic processes are roused" (p. 120). A similar idea was previously defended by Head (1920). These sound proposals were based on very scarce data (due to the scientific limitations of the epoch) mainly obtained from behavioral observations, and lacked specificity on the mechanisms by which the thalamus evaluated sensory inputs as emotional, or on the nuclei involved. However, Lashley, explicitly referring to this proposal, indicated a decade later that "the supposed evidence that the thalamus adds the affective or emotional character to sensations breaks down completely when subjected to critical analysis" (Lashley, 1938, p. 60). In parallel, the first influential model of the emotional brain was published by Papez (1937). In it, the key structure in charge of evaluating and labeling sensory inputs as emotional was not the thalamus but the hypothalamus and other brain structures: "the sensory excitations ... receive their emotional coloring from the concurrent processes of hypothalamic origin which irradiate them from the gyrus cinguli” (p. 729). Later, MacLean (1949), whose model of the emotional brain was strongly based on Papez's, successfully recovered the term "limbic" (coined by Broca in 1878) to refer to this "system" or circuit whose structures are in the limbo or intermediate area between brainstem and cortex. The limbic system, as the Papez's circuit, included the thalamus, but its function in both models was connective and secondary. The central element of the MacLean model was, instead, the hippocampus.

This "golden age" of the study of emotion within the field of neuroscience (i.e., the first half of the 20th century) was followed by a steady period in which the limbic system concept dominated and was not significantly compromised by new findings or proposals. The situation changed in the final years of the 20th century, when some influential postulates displaced the epicenter of the emotional brain from the hypothalamus or the hippocampus, as in Papez's or MacLean's models, to other structures. For example, LeDoux (1992) signaled the amygdala as a core element of the emotional brain, proposing at the same time some strong and sound reasons to overcome the limbic system model, and Damasio (1994) stressed the crucial role of the vPFC (whereas the amygdala was present in MacLean's model — not in Papez's, who explicitly indicated that "its function is unknown", 1937, p. 742-along with the vPFC, their role was not as central as in contemporary affective neuroscience). This is currently the dominant view since, as indicated, these structures have repeatedly been proposed to be involved in the initial emotional evaluation and labeling of visual inputs. In any case, this current view inherits from the Papez-limbic age the idea of the thalamus as a mere connecting hub from sensory organs to other brain structures, or between different brain structures. Indeed, thalamic nuclei have been largely ignored as recording placement during the 60-year history of human intracranial exploration of emotion, despite they have been repeatedly accessed for stimulation scopes (for a review, see Guillory \& Bujarski, 2014). Similarly, noninvasive studies employing hemodynamic techniques have focused their regions of interest (ROIs) on the thalamus only in exceptional cases, as we are about to see.

During the last century (1920-2020), the number of article titles in which both the words amygdala and emotion appear is 405 according to Google Scholar, more than 30 times the number of those including the words emotion and thalamus or any of its visual nuclei, which is 14 (search made in April 2021). Already in 2008, 385 studies recording amygdala responses to emotional stimuli through PET or fMRI existed (Costafreda et al., 2008). Table 2 shows a summarized review of the human studies 
Table 2. Studies reporting significant effects of emotional visual stimuli (as compared to neutral) on thalamic activity (1920-2020).

\begin{tabular}{|c|c|c|c|c|c|c|c|c|c|}
\hline Authors & Year & $\begin{array}{l}\text { Stimulus } \\
\text { format }\end{array}$ & $\begin{array}{l}\text { Type of } \\
\text { task }\end{array}$ & $\begin{array}{l}\text { Effect } \\
\text { location* }\end{array}$ & Authors & Year & Stimulus format & $\begin{array}{l}\text { Type of } \\
\text { task }\end{array}$ & $\begin{array}{l}\text { Effect } \\
\text { location* }\end{array}$ \\
\hline Anders et al. & 2004 & Scenes & Indefinite & Thalamus & Lichev et al. & 2015 & Faces & Implicit & Thalamus \\
\hline Britton et al. & 2006 & Scenes (video) & Explicit & Thalamus & Liddell et al. & 2005 & Faces & Implicit & Pulvinar \\
\hline Brown et al. & 2012 & Scenes & Implicit & Thalamus & Lindner et al. & 2015 & $\begin{array}{l}\text { Conditioned } \\
\text { geom. shapes }\end{array}$ & Indefinite & Thalamus \\
\hline Bühler et al. & 2008 & Scenes & Indefinite & Thalamus & $\begin{array}{l}\text { Mizuno-Matsumoto } \\
\text { et al. }\end{array}$ & 2013 & Scenes + sounds & Indefinite & Thalamus \\
\hline Critchley et al. & 2000 & Faces & Impl-Expl & Pulvinar & Morris et al. & 1998 & Faces & Implicit & Pulvinar \\
\hline Daley et al. & 2020 & Scenes & Implicit & Thalamus & Morris et al. & 1997 & Faces & Implicit & Pulvinar, $A L$ \\
\hline Das et al. & 2005 & Faces & Indefinite & Thalamus & Mourão-Miranda et al. & 2003 & Scenes & Explicit & Thalamus \\
\hline De Gelder et al. & 2004 & Body gestures & Indefinite & Pulvinar & Norris et al. & 2004 & Scenes & Explicit & Thalamus \\
\hline $\begin{array}{l}\text { De Gelder and } \\
\text { Hadjikhani }\end{array}$ & 2006 & Body gestures & Indefinite & Pulvinar & Nummenmaa et al. & 2008 & Scenes & Explicit & Thalamus \\
\hline Domes et al. & 2010 & Scenes & Explicit & Thalamus & Padmala et al. & 2010 & Faces & Implicit & Medial pulv. \\
\hline Duan et al. & 2010 & Faces & Indefinite & Thalamus & Paret et al. & 2014 & Scenes & Implicit & Thalamus \\
\hline Dunsmoor et al. & 2016 & Faces & Explicit & Thalamus & Phillips et al. & 1997 & Faces & Implicit & Thalamus \\
\hline Edmiston et al. & 2013 & Scenes & Indefinite & Thalamus & Pichon et al. & 2008 & Body gestures & Implicit & Thalamus \\
\hline Fichtenholtz et al. & 2004 & Scenes & Impl-Expl & Thalamus & Rea et al. & 2011 & Faces & Implicit & Thalamus \\
\hline $\begin{array}{l}\text { Frank and } \\
\text { Sabatinelli }\end{array}$ & 2014 & Scenes & Indefinite & $\begin{array}{l}\text { MD, } \\
\text { pulvinar }\end{array}$ & Sambuco et al. & 2020 & Scenes & Indefinite & Post. thal. \\
\hline $\begin{array}{l}\text { Garrett and } \\
\text { Maddock }\end{array}$ & 2006 & Scenes & Explicit & Thalamus & Scharpf et al. & 2010 & Scenes & Indefinite & $\begin{array}{l}\text { Pulvinar, } \\
\text { thalamus }\end{array}$ \\
\hline George et al. & 1995 & Faces & Explicit & Thalamus & Schlochtermeier et al. & 2013 & Scenes & Explicit & Thalamus \\
\hline Goldin et al. & 2005 & Scenes (video) & Explicit & Thalamus & Shafer et al. & 2012 & Scenes & Implicit & Thalamus \\
\hline Goldin et al. & 2008 & Scenes (video) & Impl-Expl & Pulvinar & Siman-Tov et al. & 2009 & Faces & Implicit & Pulvinar \\
\hline Grosbras and Paus & 2006 & Faces, hands & Indefinite & Thalamus & Stark et al. & 2005 & Scenes & Explicit & Thalamus \\
\hline Günther et al. & 2017 & Faces & Implicit & Thalamus & Stark et al. & 2004 & Scenes & Explicit & Thalamus \\
\hline Hakamata et al. & 2016 & Faces & Implicit & Pulvinar & Stark et al. & 2003 & Scenes & Indefinite & Thalamus \\
\hline Hermann et al. & 2007 & Scenes & Indefinite & Thalamus & Straube et al. & 2010 & Scenes (video) & Indefinite & Thalamus \\
\hline Holtmann et al. & 2013 & Faces & Implicit & Thalamus & Surguladze et al. & 2003 & Faces & Implicit & Thalamus \\
\hline Kang et al. & 2016 & Scenes & Indefinite & Thalamus & Suslow et al. & 2010 & Faces & Implicit & $\begin{array}{l}\text { Thalamus, } \\
\text { MD, pulvinar }\end{array}$ \\
\hline Karama et al. & 2011 & $\begin{array}{l}\text { Scenes } \\
\text { (video) }\end{array}$ & Explicit & Thalamus & Takahashi et al. & 2004 & Scenes & Explicit & Thalamus \\
\hline Kehoe et al. & 2012 & Scenes & Implicit & Thalamus & van den Stock et al. & 2011 & Body gestures & Implicit & LGN, pulvinar \\
\hline Kim et al. & 2017 & Scenes (video) & Impl-Expl & Thalamus & van Dillen et al. & 2009 & Scenes & Indefinite & Pulvinar \\
\hline $\begin{array}{l}\text { Lane, Reiman, } \\
\text { Ahern, et al. }\end{array}$ & 1997 & Scenes (video) & Explicit & Thalamus & Walter et al. & 2008 & Scenes & Implicit & Medial thal. \\
\hline $\begin{array}{l}\text { Lane, Reiman, } \\
\text { Bradley, et al. }\end{array}$ & 1997 & Scenes & Explicit & Thalamus & Waugh et al. & 2010 & Scenes & Explicit & Thalamus \\
\hline T. M. C. Lee et al. & 2005 & Faces, scenes & Explicit & Thalamus & Wehrum et al. & 2013 & Scenes & Explicit & Thalamus \\
\hline Levar et al.** & 2017 & Scenes & Explicit & Thalamus & Williams et al. & 2001 & Faces & Implicit & Thalamus \\
\hline \multirow[t]{2}{*}{ Liberzon et al. } & 2000 & Scenes & Impli-Expl & Dienceph & Winston et al. & 2003 & Faces & Implicit & $\begin{array}{l}\text { Lat. post. } \\
\text { thalamus }\end{array}$ \\
\hline & & & & & Wright et al. & 2004 & Scenes & Indefinite & Thalamus \\
\hline
\end{tabular}

Note. Inclusion criteria: (a) human adult participants free of affective, psychotic disorders or pharmacological treatments (only control participants were considered if the study included clinical samples), (b) a neutral condition along with emotional and (c) visual stimuli (faces, scenes, animals, etc.). The search was carried out in PubMed, Google Scholar, and Neurosynth until April 30, 2021. The search terms in PubMed and Google Scholar included different combinations of the terms PET, fMRI, EEG, MEG, emotion, emotional, visual, neutral, thalamus, "lateral geniculate," pulvinar. Neurosynth provides several closed tags, and we reviewed all studies under the "emotional stimuli" tag; additionally, we reviewed articles resulting from targeting three distributed locations in the posterior thalamus. An expanded version of this table (including more details on sample size, stimuli, task, observed effects, or the coordinates showing peak effects) is available at the Open Science Framework (https://osf.io/zvuj5/).

$\mathrm{AL}=$ anterolateral thalamic nucleus; $\mathrm{LGN}=$ lateral geniculate nucleus; $\mathrm{MD}=$ mediodorsal thalamic nucleus; $\mathrm{VA}=$ ventral anterior nucleus.

${ }^{*}$ As labeled by the authors.

** This study finds Emo $<$ Neu in one of the thalamic coordinates; the rest of studies report Emo $>$ Neu.

Boldfaced lines: studies including a ROI in the thalamus (whole brain strategy in the rest of studies).

Italicized lines: studies employing PET (positron emission tomography); the rest employed fMRI (functional magnetic resonance imaging). 
reporting significant differences between the thalamic response to emotional and to neutral visual stimuli. A total of 68 studies were detected after a systematic review (see details of the search procedure in Table 2's footnote). Although only a portion of these studies defined a ROI in the thalamus (23.53\%), as indicated, several experiments employed a whole brain analytical strategy that allowed the analysis of its activity. As can be appreciated in the expanded version of the table, the direction of thalamic activation differences is "Emo $>$ Neu" in almost all cases $(98.53 \%)$, and it is observed regardless of the type of emotional visual stimuli (faces, scenes, bodies, etc.) and the type of task (explicit, asking for the emotional categorization of stimuli, or implicit, asking for nonemotional characteristics such as gender of emotional expressions). However, it is important to note that these studies employed hemodynamic techniques (fMRI or PET), and due to the spatial resolution limitations of the majority of scanners, this thalamic sensitivity to emotional stimulation is not located in specific nuclei except in a few studies $(26.47 \%)$, the pulvinar (the largest thalamic nucleus in humans and other mammals) being the most recurrent. This limitation, along with usual analytic strategies (e.g., defining relatively large cluster sizes), hinder the detection of small thalamic nuclei activity, such as that in the lateral geniculate nucleus (but see van den Stock et al., 2011). More importantly, these recording techniques also present low temporal resolution, thus brief responses are difficult to detect and, in any case, it is not possible to determine whether the recorded thalamic response was produced in the initial ascending course of visual information or in later recurrent phases (or in both). The few existing studies recording electromagnetic brain signals, characterized by their high temporal resolution, point to the former possibility, though results should be taken with certain caution due to their limitations in spatial resolution. Thus, magnetoencephalographic (MEG) data show gamma band enhancement - an index of increased activity-in the thalamic area from $20 \mathrm{~ms}$ in response to fearful facial expressions (this latency is not a discrete onset of activity, but the beginning of the time frequency analysis window; Luo et al., 2007), and another MEG study describes increased amplitudes of the thalamic response to emotional faces at $35 \mathrm{~ms}$ (Liu et al., 2015).

The visual thalamus comprises several structures that may be classified as first-order nuclei, which receive visual information mainly and directly from the retina, as well as higher order structures, which receive main visual inputs after one or more synapses - in other words, after passing through one or more brain structures. As will be described next, the lateral geniculate nucleus (a first-order structure) as well as the pulvinar and the thalamic reticular nucleus (TRN; both second-order structures that receive visual information from first-order structures, not from the retina) are the main nuclei of the thalamus in charge of processing visual information (but not exclusively visual in the case of the pulvinar and TRN; see Figure 3). At least in the initial, fastest visual processing, which is the main focus of this review, pulvinar and geniculate routes are parallel and relatively independent. For obvious reasons, the physiological properties of these nuclei have been scarcely studied through intracranial recordings in humans, but data from nonhuman primates (relatively numerous mostly on macaques and marmosets) provide information widely generalizable to our species. Crucially, as we are about to see, the three structures can modulate the information they receive so that it may be amplified or filtered prior to its submission to other brain areas, and their structure and function make them solid candidates to be IESs. Whereas they are described individually in the next sections, they are proposed to form an IES network capable of influence, largely in parallel, the activity of subsequent brain regions. With this idea in mind, and although this issue will be further discussed in the final section, we will emphasize mutual interconnections in the following sections.

\section{First-Order Visual Thalamus: Lateral Geniculate Nucleus}

\section{Main Characteristics and Interconnections}

As schematized in Figure 3, the human lateral geniculate nucleus (LGN) is a S-shaped structure, its neurons presenting a retinotopic distribution. LGN receives direct inputs from the retina through ganglion cells, and most geniculate neurons receiving them directly project to the visual cortex, with no intermediate neurons (Weyand, 2016). These geniculo-cortical neurons, also named relay neurons, are of three different typesparvocellular (P), magnocellular (M), and koniocellular (K)and are distributed in different layers. Each of these relay cells receive dominant inputs from one specific ganglion retinal cell, but also secondary inputs from other two or three ganglion cells (Ghodrati et al., 2017) that may be of different types (up to date, at least 17 types of ganglion cells have been described in the primate visual system; Grünert \& Martin, 2020). All three types of relay neurons would act mainly as focal processors (see Figure 2), but there are several differences among them. Thus, $\mathrm{P}$ cells are more sensitive than $\mathrm{M}$ cells to color, higher spatial frequencies (characteristic of fine details, lines, or contours), and lower temporal frequencies, and have lower sensitivity to luminosity contrast; whereas $\mathrm{M}$ cells are more responsive to luminosity contrast, lower spatial frequencies (they provide a sort of blurred image), higher temporal frequencies, and are more involved in motion processing, among other processing differences (Derrington \& Lennie, 1984; DeYoe \& van Essen, 1988; Maunsell \& Newsome, 1987; Schiller \& Malpeli, 1978). K neurons, much less studied, are a physiologically heterogeneous group of cells; some of them exhibit motion and orientation selectivity, others are more sensitive to color, and even part of them seem unresponsive to visual information (Martin \& Solomon, 2019). In general, K cells present lower spatial selectivity and longer response latencies compared to $\mathrm{P}$ and $\mathrm{M}$ cells (Zeater et al., 2019). Geniculo-cortical projections are mainly directed to the striate cortex $(\mathrm{P}, \mathrm{M}$, and $\mathrm{K}$ cells reaching different layers of this cortical area), but also to the extrastriate visual cortex (V2, V3, V4, and MT receive geniculate inputs, mainly from K cells; Ghodrati et al., 2017). This direct transmission of information from the retina to visual cortices through a twoneuron design facilitates rapid transmission of information.

As indicated, this relay role classically stressed for the LGN in the literature, and considered relatively passive, is actually modulated by several factors. First, only about $10 \%$ of synaptic 

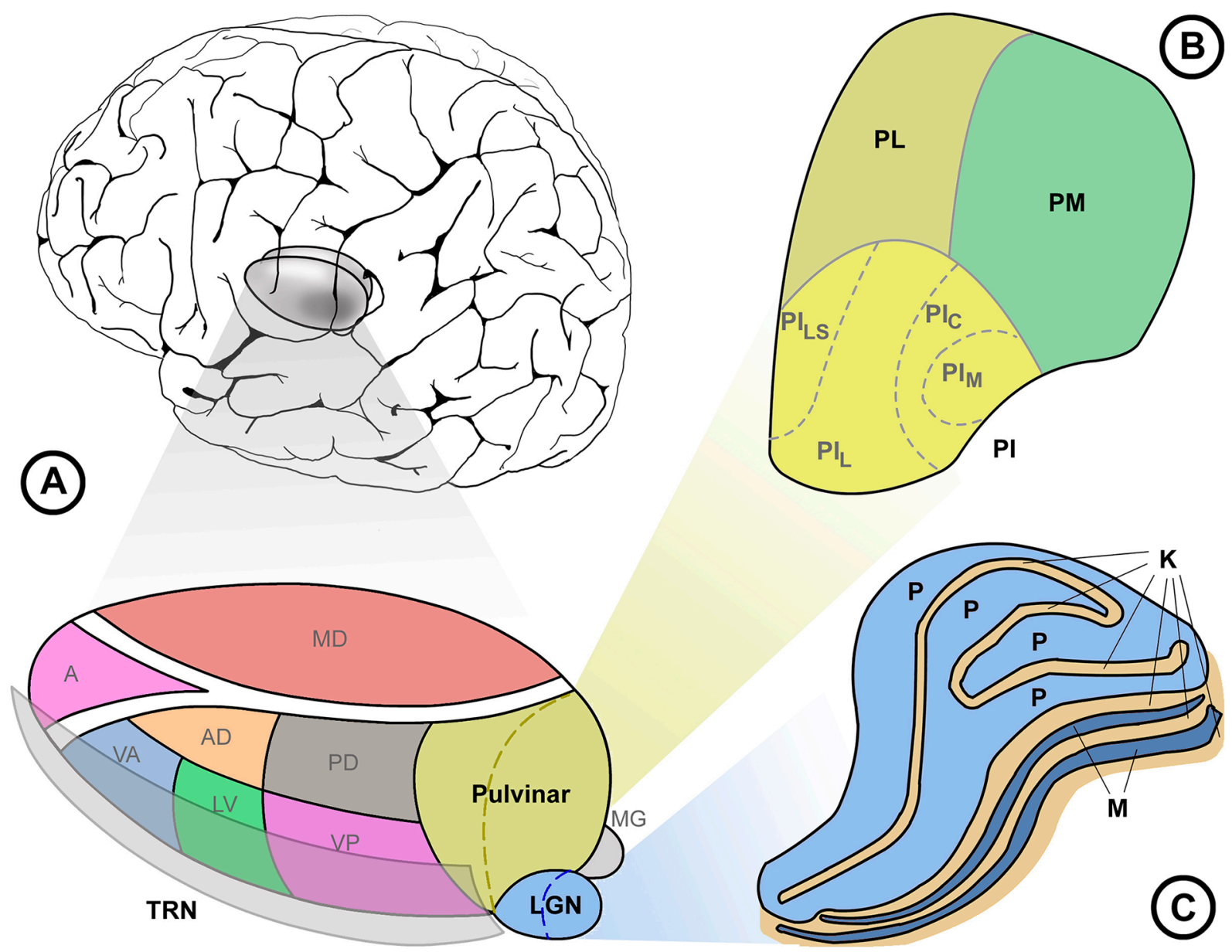

Figure 3. Left human thalamus, highlighting the structures described.

Note. A. Thalamus location in a transparent lateral-posterior view of the brain and main external thalamic nuclei. Dashed lines show the coronal sections depicted in B and C: thalamic reticular nucleus (TRN), lateral geniculate nucleus (LGN).

B. Coronal section of the human pulvinar: lateral pulvinar (PL), medial pulvinar (PM), inferior pulvinar (PI); subscripts: lateral shell (LS), lateral (L), central (C), medial (M). C. Coronal section of the human LGN: parvocellular layer (P), magnocellular layer (M), koniocellular layer (K).

Whereas schematized, coronal sections of LGN and pulvinar are represented with the approximate shape they present in humans (see Cola et al., 1999; Usrey \& Alitto, 2015). Other acronyms: $\mathrm{A}=$ anterior, $\mathrm{MD}=$ mediodorsal, $\mathrm{AD}=$ anterior dorsal, $\mathrm{PD}=$ posterior dorsal, $\mathrm{VA}=$ ventral anterior, $\mathrm{LV}=$ lateral ventral, $\mathrm{VP}=$ ventral posterior, $\mathrm{MG}=$ medial geniculate nuclei.

inputs to LGN neurons proceed from the retina (Ghodrati et al., 2017). On one hand, the visual cortex sends feedback neurons to LGN and can modulate its activity (e.g., Marrocco et al., 1996); on the other hand, LGN neurons receive subcortical inputs, which account for approximately $30 \%$ of LGN synapses (Ghodrati et al., 2017). These inputs, of excitatory and inhibitory nature, come from nuclei controlling visuomotor function, such as the superior colliculus, the parabigeminal nucleus (both reaching $\mathrm{K}$ cells), and the nucleus of the optic tract (K, $\mathrm{M}$, and $\mathrm{P}$ cells), but additionally from nuclei also involved in general arousal and vigilance levels such as the tuberomammillary nucleus (reaching $\mathrm{K}$ cells) and the pedunculopontine tegmentum $(\mathrm{K}, \mathrm{M}$, and $\mathrm{P}$; for more details on these subcortical inputs, see Casagrande et al., 2005; Zeater et al., 2019).

Second, retinal ganglion cells do not only innervate relay neurons (i.e., $\mathrm{P}, \mathrm{M}$, and $\mathrm{K}$ cells), they also send projections to LGN interneurons, which represent approximately $25 \%$ of LGN neurons. These cells, of GABAergic (inhibitory) nature, are multidirectional (i.e., its neurites may act both as "dendrites" and as "axonic terminals" in different situations) and present a complex pattern of connections with hundreds of other interneurons and different types of both retinal ganglion cells and relay cells (mostly M; Casagrande et al., 2005). Interestingly, due to this ramification, each interneuron processes an aggregation of numerous receptive fields that, together, may cover half of the visual field approximately (Morgan \& Lichtman, 2020). This rich and variate synaptic architecture allows interneurons to participate in global processing (Morgan \& Lichtman, 2020), and they may be conceptualized as in situ analyzers that strongly modulate the activity of LGN outputs (Govindaiah \& Cox, 2006). Therefore, the possibility that interneurons constitute, at least partially, the global processor previously discussed (see Figure 2), despite unexplored, should not be discarded. Interneurons can act at extremely high speed in response to ganglion inputs in certain circumstances $(1 \mathrm{~ms}$; Blitz \& Regehr, 2005), so this global processing would not compromise the IESs 


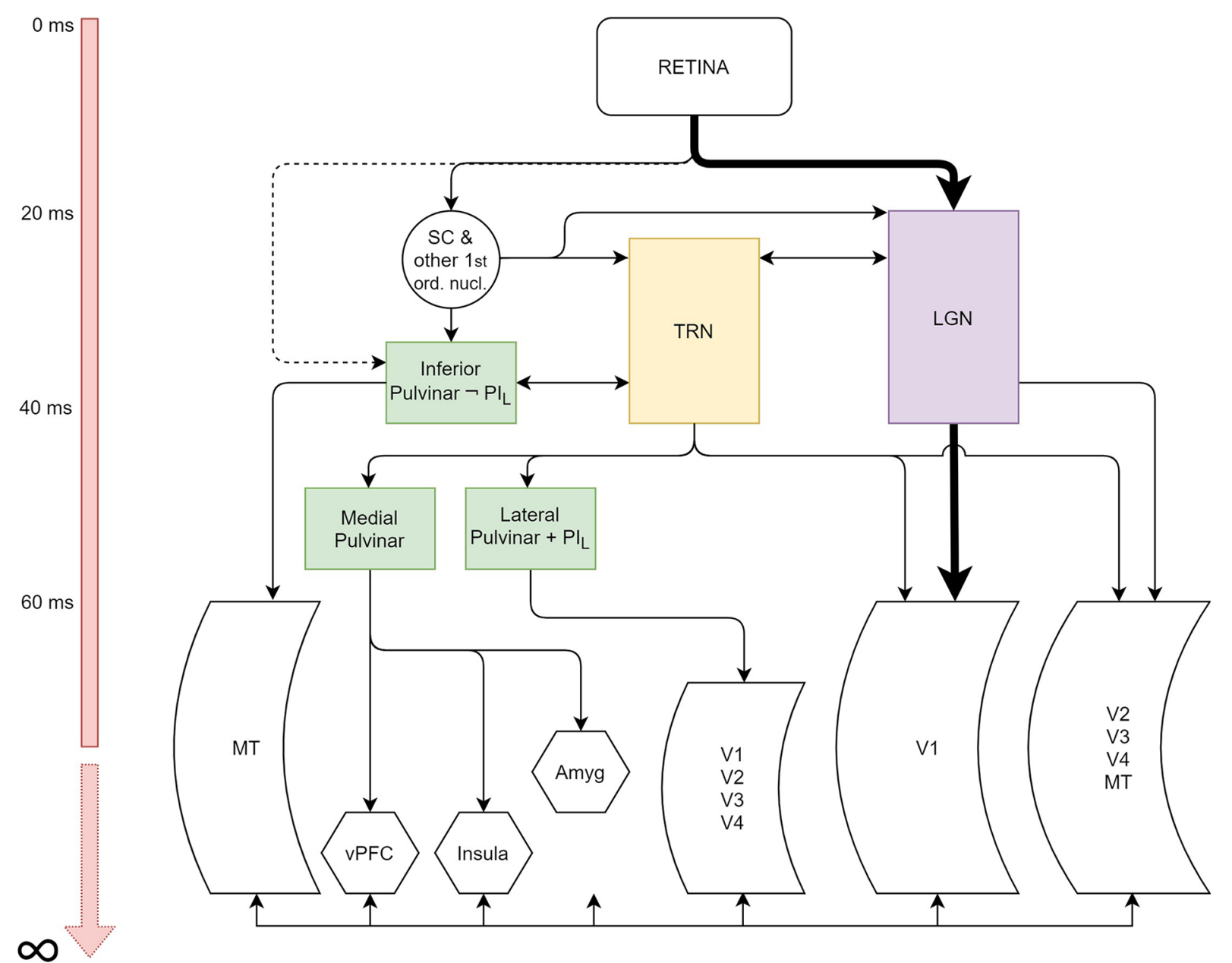

Figure 4. Ascending route from the retina to the main visual and emotional processing structures in adult humans, including an approximate temporal scale regarding the arrival time of information to each processing level.

Note. Only forward and "horizontal" connections are represented (note that rich backward projections exist, as explained in the main text, not represented).

Rectangular and colored structures $=$ thalamic; circular $=$ subcortical visual processing nuclei; arcuate $=$ visual cortices; hexagonal $=$ emotion processing structures. Dashed line $=$ vestigial ascending route; thick line = preferential ascending route.

SC = superior colliculus; LGN = lateral geniculate nucleus; TRN = reticular thalamic nucleus; vPFC = ventral prefrontal cortex; PIL = inferior pulvinar, lateral portion (PIL does not receive SC nor retinal inputs, and projects to visual cortices, so its connections are common to lateral pulvinar); $\neg=$ not.

requirement of short latency. However, as discussed later, current data point to another thalamic nucleus, TRN (alone, or coordinately with interneurons), as the probable main global processor linked to LGN activity.

\section{LGN as an Active Processor}

This rich interconnectivity of LGN (ascending routes are summarized in Figure 4) enables its role as an active processor capable of modulating the information conveyed by retinal ganglion cells prior to its retransmission to visual cortices. Indeed, data from fMRI reveal that, like visual cortices, the activity of human LGN is enhanced towards attended stimuli and attenuated towards unattended stimuli (O'Connor et al., 2002). fMRI data also show that human LGN increases its activity in response to complex shapes and figures versus ground processing, regardless of whether these stimuli are attended or not (Poltoratski et al., 2019). Although fMRI data may reflect a recurrent corticogeniculate activation (Poltoratski et al., 2019), electrophysiological LGN recordings in macaques point to the possibility of local, precortical modulation in some circumstances. For example, the spike rate (i.e., the frequency of action potentials) of $\mathrm{M}$ and $\mathrm{P}$ cells rapidly increases in response to attended stimuli (a line with a specific orientation) appearing in their corresponding receptive field, as compared to nonattended stimuli (a line with another orientation; macaque: McAlonan et al., 2008). The latency of the attended versus nonattended response differences is rapid enough to discard the involvement of the visual cortex in this early attentional effect: 26 and $37 \mathrm{~ms}$ average from stimulus onset in $\mathrm{M}$ and $P$ cells, respectively. Together, these fMRI and intracranial data point to a key LGN role in sensory gain or sensory filtering as a function of both extrinsic variables, such as the attentional demands of the ongoing task, and intrinsic characteristics of the stimulus, such as its configurational characteristics. 
Therefore, the way by which the LGN modulates retinal inputs is spike rate. Since the LGN is poorer in spatial processing terms than the retina, it compensates for this deficit through richer signals in temporal terms than those transmitted by ganglion cells (Weyand, 2016). Depending on the visual characteristics of the stimulus in each receptive field, LGN relay cells may reproduce or not the spike arriving from ganglion cells and, in the former case, the temporal distribution of spikes varies to inform on different visual features (Weyand, 2016). This mechanism allows the thalamus to carry out a sort of digital image processing, such as unsharp filtering or local contrast gain (Hirsch et al., 2015). This spike activity linearly related to the intensity of the stimulus is called tonic firing. Importantly, as indicated before, this tonic firing may be modulated by extrinsic or intrinsic characteristics of current stimulation.

Tonic firing may also be modulated by relatively steady neural states. For example, data exist showing shorter response latency in LGN neurons when the brain presents a desynchronized state (characterized by a high frequency and low amplitude electrical activity, reflecting enhanced vigilance) than in a synchronized state (low frequency and high amplitude, characteristic of lower vigilance situations), probably due to a global increase in membrane conductance in the former state (X. D. Wang et al., 2014). This shorter latency is also produced in different layers of V1 (see Figure 1), indicating an accumulative response speed in the visual pathway in vigilance situations. In relation to this, synchrony between LGN and V1 (this is a different concept from the previously mentioned global synchronized state of the brain) - particularly in the beta frequency band, which ranges from 12 to $30 \mathrm{~Hz}$ (relatively high) - may enhance the transmission of visual information between both structures (for review, see Saalmann \& Kastner, 2011). Another relatively steady, diffuse mechanism is the influence of certain neuromodulators such as histamine (but also others such as serotonin), which reaches relay cells through neurons proceeding from the tuberomammillary nucleus, causing an increase in the LGN transfer ratio of information from the retina. According to Casagrande et al. (2005), "histamine release is often associated with negative stimuli. Thus, one might speculate that this pathway to the LGN functions to increase the transfer ratio of retinal signals in situations where potential danger exists" (p. 204).

Along with tonic firing, LGN produces burst firing, consisting of bundles of temporally close action potentials (one spike each 4-5 ms or less, as compared with the typical gap in tonic LGN activity, often over $10 \mathrm{~ms}$; Sherman, 2001). Classically associated with sleep, when they are abundant (e.g., Livingstone \& Hubel, 1981), they may also be detected in the awake state, albeit more sporadically. In the awake animal, it has been proposed to be a sort of "wake up call" (Guido \& Weyand, 1995) that signals the appearance of a salient stimulus, LGN returning then to tonic firing mode to facilitate both the reliable transmission of information from ganglion cells to cortex and a more detailed information processing (Alitto et al., 2019; Lesica \& Stanley, 2004; Saalmann \& Kastner, 2011). As in tonic firing, the temporal characteristics of burst spikes, namely the number of burst spikes and the interspike interval, could inform on specific visual characteristics of the stimulus, such as the phase and the amplitude of spatial frequency (see Ishii \& Hosoya, 2020, regarding retinal bursts in salamanders, but probably generalizable to other visual levels and species).

As indicated, LGN is involved in complex feature processing. For example, it is able to categorize and prioritize stimuliin terms of the firing rate towards visual cortices - according to their shape. Thus, P cells ( $\mathrm{M}$ and $\mathrm{K}$ cells have not been explored in this respect) increase their spike rate, especially burst spikes, in response to a particular geometrical form, but not to others, $40 \mathrm{~ms}$ after onset (macaque: Ortuño et al., 2014). This prioritization may be extrinsic (i.e., primate subjects are conditioned, through juice or water administration, towards a particular shape) or intrinsic (i.e., the characteristics of the stimulus itself, rather than instructions or conditioning). In this latter case, an increase in burst occurrence rates is observed around $40 \mathrm{~ms}$ after the onset of novel shapes within a sequence of "standard" (more frequent) shapes (Ortuño et al., 2014). Also in the intrinsic modality, burst firing increases around $20 \mathrm{~ms}$ after luminosity or motion changes in naturalistic shapes (frames of forests or people) as compared to similar changes in artificial shapes (frames composed of black and white pixels randomly distributed; cat: Lesica \& Stanley, 2004). Although only P cells (or X cells, in cats) have been explored up to now with regard to shape recognition, similar results should be observed in other LGN relay cell types, as indicated by Ortuño et al. (2014). Whether emotional shapes are capable of activating LGN neurons to a greater extent than nonemotional ones has not been explored through intracranial recordings, but hemodynamic data in humans point to this (although these results could also reflect recurrent cortico-geniculate LGN activations, rather than initial evaluation; van den Stock et al., 2011). In sum, LGN appears to meet the criteria to be considered an IES - an adequate response latency (20-40 ms in humans) and a visual processing architecture-but it is likely complemented by other first- or secondorder structures.

\section{Second-Order Visual Thalamus}

\section{Pulvinar}

The pulvinar, the largest structure in the thalamus, is crucially involved in a wide set of visual and cognitive processes, and its lesion causes important dysfunctions regarding saccades, orienting responses, filtering irrelevant visual information, or visually guiding motor behavior, among other alterations (Bridge et al., 2016; Saalmann \& Kastner, 2011). The pulvinar is actually a set of nuclei, rather than a single nucleus, rostrally adjacent to LGN (see Figure 3). Despite this proximity and the similarities of some LGN and pulvinar cells at the connectivity and cytoarchitectonic level (Huo et al., 2019), no direct connections have been reported between them, but indirect through third-party structures, as explained later. Therefore, they seem to work largely in an independent and parallel fashion, at least in early, ascending information processing. The pulvinar is only partially devoted to vision and, in humans and other primates, the visual pulvinar is located in its lateral (PL) and inferior parts (PI). These areas are relatively smaller in humans than in other 
primates (approximately $1 / 4$ vs. $2 / 3$ of pulvinar volume, respectively; Arcaro et al., 2015; Baldwin et al., 2017). The other two grand regions of the pulvinar are anterior, involved in somatosensory processing, and medial (PM), bidirectionally connected to multimodal brain areas such as the amygdala, the prefrontal cortex, and several temporal and parietal regions (Bridge et al., 2016).

This pulvino-amygdalar connection has been proposed as a short and fast route for emotional processing, enabling visual information to rapidly reach the amygdala without the involvement of the visual cortex. However, it is important to mention that, contrary to LGN, in which interneurons interconnect different relay neurons, local interconnections among different pulvinar nuclei have not been reported. Thus, a direct and local transmission from PI (the pulvinar portion that receives ascending visual inputs) to PM (which connects with the amygdala but does not seem to receive these inputs in primates, data suggesting this possibility being controversial or not verified; Bridge et al., 2016) has not been reported. Communication among pulvinar areas is a scarcely explored issue, but it is probably carried out at the TRN and/or at the cortical level, both bidirectionally connected with several pulvinar areas, as explained later. In other words, this pulvinar path from retina to amygdala is not as direct and fast as sometimes assumed (see also Pessoa \& Adolphs, 2010, for a thorough review), and may explain the relatively long response latencies in the latter structure.

Both PL and PI, devoted to visual processing, contain one or more retinotopic maps (Halassa \& Kastner, 2017). The latter may be further subdivided into four or five regions, depending on the primate species (Baldwin et al., 2017). Although the nomenclature is variable from one author to another, the most common is, from the lateral to the midline PI: the lateral shell, lateral, central, medial, and posterior parts (Cola et al., 1999; Gattass et al., 2018), with certain variations in humans (e.g., posterior PI is absent in human species; Cola et al., 1999; see Figure 3). Importantly, medial PI (also present in humans) is the only pulvinar subdivision receiving direct retinal (weak) inputs, along with superior colliculus inputs (a first-order, non-thalamic structure), and exclusively projects to the dorsal visual cortical pathway, concretely to area MT (marmoset: Warner et al., 2010; see Figures 1 and 4). This retino/colliculopulvino-cortical route shows its peak functionality in newborns and, after a few months, the LGN becomes the dominant thalamo-cortical visual output, axonal afferences from medial Pl to MT experiencing then a swift anatomical regression (Warner et al., 2012). This route is significantly involved in visual processing in newborns, particularly in motion detection, and seems essential in the early acquisition of the idiosyncratic and sophisticated visomanual control in primates (marmoset: Mundinano et al., 2018). In adult primates, in which the superior colliculus is the main visual input to medial PI, a residual of this pulvinar-MT path may remain and is characterized by its fast transmission speed: total latency in the $\mathrm{SC}$-pulvinar-MT route is $5 \mathrm{~ms}$ average (macaque: Berman $\&$ Wurtz, 2010). In human adults, this route has been proposed to contribute to blindsight, a sort of unconscious vision caused by lesions in the striate cortex, although this contribution is controversial (see Kinoshita et al., 2019; but see Ajina \& Bridge, 2018; Schmid, 2010).

Some other PI areas also receive afferences from the superior colliculus (lateral PI is not among them, as later explained), which is the main ascending visual input to the pulvinar (see Figure 4), and the reason to consider it a second-order visual structure (e.g., Usrey \& Alitto, 2015). Being a second-order structure is relevant to our purpose of describing an IES, since its processing latencies are longer than those of LGN (16 ms longer, on average, measuring the response to the same stimuli in pulvinar and LGN macaque: Bender, 1982). However, main visual inputs of the visual pulvinar are visual cortices. Thus, V1 to V4 (see Figure 1), or early ventral pathway, innervate PL and lateral PI (the only PI subdivision directly connected to these visual cortices; Bridge et al., 2016), whereas MT and other early cortical areas of the dorsal pathway send efferences to medial and posterior PI (Bridge et al., 2016; Gattass et al., 2018). Innervations are mutual: these PI subdivisions send projections to the same visual areas from which they receive inputs. Thus, the pulvinar is mainly considered a cortico-cortical intercommunication and coordination hub (Eradath et al., 2020; Jaramillo et al., 2019). Particularly, this role as a cortical hub could consist in regulating "cortico-cortical information flow by modifying synaptic efficacy within and across visual cortical regions, rather than by relaying visual features from one area to another" (Halassa \& Kastner, 2017, p. 1673). Electrophysiological data provide another clue on the cortical preeminence over the pulvinar, since part of the visual cortex (concretely V4) leads the pulvinar in gamma synchrony (over $30 \mathrm{~Hz}$ ), a sign of attention enhancement during stimulus processing (macaque: Zhou et al., 2016).

Data from different lines of research point to a significant role of the pulvinar in emotional processing. A recent review by Soares et al. (2017) reports enhanced firing rates of primate pulvinar neurons in response to emotional stimuli such as snakes or emotional faces. Forming a sort of tandem with the pulvinar, the superior colliculus also seems sensitive to the saliency of stimulation, as will be discussed later. Although an important part of pulvinar activity is "postcortical," as indicated before, some data suggest a precortical capability of the pulvinar to discriminate salient stimuli, including emotional. Indeed, differences between faces and other visual stimuli are observed as early as 50 ms (macaque: Nguyen et al., 2013), or between snakes and other visual stimuli at $\sim 55 \mathrm{~ms}$ (macaque: van Le et al., 2013), these latencies being incompatible with a previous cortical intervention. Whereas involvement of the pulvinar in rapid emotional evaluation seems backed by experimental data, the question of whether these latencies explain the initial V1 emotional discrimination in humans requires additional research. However, there are two complementary reasons that together, and according to current data, make this unlikely. First, latencies in the human visual structures could be longer than in the macaque (the accumulated difference in V1 is $\sim 20 \mathrm{~ms}$; Pessoa \& Adolphs, 2010). Second, as previously explained and schematized in Figure 4, pulvinar nuclei innervating V1 and subsequent ventral visual cortex areas (PL and lateral PI) seem not to receive ascending visual inputs (although this issue is 
controversial; Bridge et al., 2016), so something similar to what we explained before regarding the colliculo-pulvino-amygdalar route occurs in this case. Thus, PI, the pulvinar area which receives the visual ascending inputs (except lateral PI, as also indicated), can only indirectly trigger any activity at V1, V2, or V3, probably through TRN or cortico-cortical connections. In sum, the visual pulvinar could be a complementary IES acting with some delay with respect to LGN ( $\sim 10$ to 20 ms more, yielding 40-60 ms latencies), and would send additional emotionlabeled information to both common and different structures to those reached by the LGN (see Figure 4).

\section{Thalamic Reticular Nucleus}

The thalamic reticular nucleus (TRN) is a lamina of GABAergic (inhibitory) neurons that surrounds the thalamus laterally (see Figure 3). This sort of shell, close to the body of the thalamus, is indeed an intricate net or reticula that interconnects thalamic nuclei and connects them to nonthalamic structures (Guillery \& Harting, 2003; Kimura, 2014, 2017). Thus, each portion of the TRN is neurally and functionally linked to the thalamic nuclei it covers, often presenting a topographical organization (Halassa \& Kastner, 2017). The visual portion, organized in retinotopic maps (Bragg et al., 2017), corresponds to its posterior part. It is bidirectionally connected with the pulvinar and the LGN, interconnecting them, as already indicated (Saalmann \& Kastner, 2011). Additionally, this visual portion receives visual cortical information through collateral inputs from cortico-thalamic neurons (Bragg et al., 2017; Guillery \& Harting, 2003). Globally, the TRN also receives direct afferences from brainstem nuclei, basal ganglia, ventral and dorsolateral prefrontal cortices, and the amygdala (Ghodrati et al., 2017), so it manages a relatively wide range of information.

The interaction of visual TRN with LGN and pulvinar has been scarcely studied, especially in the latter case. With respect to LGN, despite TRN neurons being GABAergic, their final effects are complex and not exclusively inhibitory: their direct synapses with LGN relay cells cause indeed inhibition but, since they also innervate interneurons, whose effect is inhibitory, they may also produce a disinhibitory effect on relay cells (Ghodrati et al., 2017). Each TRN neuron reaches multiple LGN cell types and layers regardless of their typology or ocularity, and this transversality and nonspecificity would enable interactions between different visual pathways (M, P, K), again pointing to the involvement of the visual thalamus in relatively complex processing (Bragg et al., 2017). With regard to its interconnections with the pulvinar, which involve different TRN portions to those interconnected to LGN, data are scant. Recently, the pulvinar-TRN network has been linked, along with their cortical interconnections, with cognitive computations associated with decision making and, more concretely, with decision confidence (Jaramillo et al., 2019).

This high interactivity, both at the thalamic and at the extrathalamic level, makes TRN a relevant global processor and modulatory element (Bragg et al., 2017). Indeed, it has been defined as an "attentional gate" that regulates the visual output of the thalamus before reaching the cortex and other structures (McAlonan \& Brown, 2002). In the case of visual processing, it could contribute to guide the attentional effects previously described in LGN relay neurons. Thus, while the visual input reaches $\mathrm{M}$ cells prior to TRN cells (and later, P cells; K cells have not been studied), the attentional effects are observed earlier in the latter. Indeed, the effect of presenting an attended stimulus as compared to a nonattended one in the corresponding receptive field is observed $4 \mathrm{~ms}$ earlier in TRN cells than in M cells (22 and $26 \mathrm{~ms}$ on average, respectively; $37 \mathrm{~ms}$ in P cells; macaque: McAlonan et al., 2008). In other words, the TRN seems to guide the attention-related activity of relay cells. The mechanism of action would start with a decrease in the disinhibitory effect of TRN. Thus, the arrival of the attended input triggers a reduction in TRN activity - as compared to the activity elicited by nonattended stimuli-and, since this nucleus is inhibitory in its direct synapses with LGN relay cells, the immediate consequence of this reduction is that the latter increase their activity (McAlonan et al., 2008).

These data are of extreme importance since they signal TRN not only as an in situ processor, but also as a fast and early processor compatible with the speed required for an IES. Relatedly, the TRN plays an important role in the suppression of distractors during attentional focalization (Halassa \& Kastner, 2017). Although these functions seem relevant in emotional processing, the involvement of TRN in it has not been explored yet, to the best of our knowledge. However, this is highly probable considering the capability of emotional stimuli to capture attention (Carretié, 2014). The fact that, as indicated before, TRN receives inputs from emotional processing structures, such as the amygdala and vPFC, points to this same hypothesis. Importantly, TRN shows long-term potentiation, a mechanism that enhances certain neural connections and is involved in memory. This potentiation seems to be regulated by burst firings of thalamocortical cells (rat: Sieber et al., 2013), although this is a scarcely explored issue. This could imply a role of the TRN in mnemonic processes, which is a necessary element that allows the online comparison of the visual input with stored relevant visual patterns. Therefore, its role regarding initial emotional evaluation seems crucial and would complement the role of the LGN and pulvinar.

\section{First-Order Nonthalamic Structures}

Just as the thalamus has often been out of the focus of main models of cognitive and affective processing, and even out of models of visual processing (Ghodrati et al., 2017), a possible limitation in any proposal on early emotional processing of visual stimuli could be to ignore other nonthalamic structures that may be involved. It is probable that each node within the ascending visual routes in which a synapse is produced develops a certain level of processing or classification of stimulation with regard to its potential risk or other saliency indicators, as well as a certain modulation of the information it receives. Therefore, the "missing link" in early emotional processing could be potentially extended to some first-order visual structures that would be part of the IES network. 
Table 3. First-order (i.e., receiving direct retinal inputs) nonthalamic nuclei in the human brain.

\begin{tabular}{ll}
\hline Nucleus & Location \\
\hline Superior colliculus & Tectum (midbrain) \\
Suprachiasmatic nucleus & Hypothalamus \\
Medial terminal accessory nucleus & Accessory optic system \\
Lateral terminal accessory nucleus & (spread, but mainly \\
Dorsal terminal accessory nucleus & tegmentum [midbrain/ \\
Interstitial nucleus of the superior fasciculus & pons]) \\
Olivary pretectal nucleus & Pretectum (midbrain) \\
Nucleus of the optic tract & \\
Anterior pretectal nucleus & \\
Medial pretectal nucleus & \\
Posterior pretectal nucleus & \\
Posterior limitans nucleus & \\
Commissural pretectal area & \\
\hline
\end{tabular}

Whereas most retinal outputs travel through the optic nerve to LGN, there are a dozen brain nuclei that also receive direct ganglion fibers (see Table 3). In most of them, the main role is associated with oculomotor function and/or motion processing, but some studies propose their involvement, to a greater or lesser extent, in cognitive functions such as attention or memory. Their role in affective processes has been scarcely studied (or not studied, in many cases), but the fact that dynamic stimuli are often emotional (predators, mates, approaching/falling objects, competitors, preys, etc.) leads to expect significant contributions at this level.

\section{Superior Colliculus (SC)}

This structure is located in the top (tectum) part of the midbrain, and is organized in six layers in mammals, the two external or superficial (SCs) receiving visual inputs from the retina and other visual structures such as the visual thalamus, visual striate and extrastriate cortices, parabigeminal nucleus (a sort of SC satellite contributing to saccade control), pretectum nuclei (discussed in the next section), as well as from the locus coeruleus (involved in the regulation of arousal; Basso \& May, 2017). The SCs is organized retinotopically (Cerkevich et al., 2014) and sends projections to $\mathrm{K}$ layers and to the pulvinar. It is involved in basic visual processing, mainly related to orienting and motion, and aimed at organizing orienting movements of the eyes and head (Krauzlis et al., 2013). Interestingly, SCs, despite not being connected to attention networks (such as fronto-parietal networks), responds differently as a function of physical stimulus saliency, what suggests an autonomous capability to detect it (White et al., 2017). Intermediate and internal layers (SCi), also organized topographically (Wurtz, 2009), are multimodal since they receive visual inputs from SCs and nonvisual sensory inputs as well. The SCi layers interact with many levels of the central nervous system, including frontal and parietal cortices (but not with the visual thalamus), and would contribute to orienting behavior and to cognitive processes such as attention or decision making (Basso \& May, 2017; Krauzlis et al., 2013).

Several data suggest that the $\mathrm{SC}$ is able to discriminate complex features. Through fMRI recordings in humans, SC responses to aversive stimuli are greater than to other visual stimuli (Almeida et al., 2015; Y. C. Wang et al., 2020). Indeed, $\mathrm{SC}$ is proposed to form a sort of tandem with the pulvinar as an early emotional detection mechanism (Soares et al., 2017). Intracranial electrophysiological data also point to the SC capability to discriminate complex shapes. For example, it responds more intensely to certain fractal forms - varying in colors, shapes, and sizes - as a function of their hedonic value previously conditioned with juice administration (macaque: Griggs et al., 2018), a discrimination which is patent at $95 \mathrm{~ms}$ from stimulus onset. This relatively long latency may be explained by proposals from other lines exploring the involvement of the SC in spatial attention. In them, the SC has been postulated to contain spatial maps of the visual context rather than to process stimulus features, and therefore would need to intercommunicate with other cerebral structures that process and evaluate these features (Krauzlis et al., 2013). According to this, the SC would act as an indexing system that pools together the signals of those structures to determine the content of perception. This idea would imply that the feature evaluation carried out by the $\mathrm{SC}$ is fruit of recurrent information. In any case, electrophysiological data are currently very scarce, and additional research is needed to characterize, both in temporal and functional terms, the involvement of the $\mathrm{SC}$ in emotional evaluation.

\section{Other Structures}

As indicated, although the main targets of ganglion cells are the LGN and, to a lesser extent, the superior colliculus, several brain nuclei also receive direct retinal inputs (see Table 3). Some of them seem less involved in rapid processing of visual stimulation, such as the suprachiasmatic nucleus of the hypothalamus, a key element in the control of circadian rhythms, or the pretectal olivary nucleus, which controls the pupillary light reflex or triggers rapid eye movements during sleep. However, most first-order nuclei, particularly those linked to oculomotor control, are indeed fast detectors of visual stimulation.

On one hand, the human accessory optic system (AOS) is a net of four nuclei also innervated by retinal ganglion cells which present large receptive fields and are direction-selective (Fredericks et al., 1988). The AOS is involved in motion processing and in the control of oculomotor mechanisms, but also in cognitive processes such as spatial memory and attention (Giolli et al., 2006). On the other hand, the six nuclei forming the pretectum also receive direct retinal inputs (Gamlin, 2006). One nucleus of the pretectum, the nucleus of the optic tract (NOT), is especially relevant since it receives inputs from the visual cortex (along with retina) and projects to the LGN, pulvinar, and TRN, as well as to AOS nuclei and to the superior colliculus, among other structures (Büttner-Ennever et al., 1996). Functionally close to the AOS, the NOT is also a part of the brain machinery that processes motion and adapts oculomotor activity to that motion (Gamlin, 2006). Indeed, and as the AOS, 
the NOT participates in cognitive processes such as attention (Büttner-Ennever et al., 1996).

\section{Discussion and Conclusions}

Figure 4 summarizes the information provided in previous sections on the main ascending routes of visual information, and the approximate timings - from stimulus onset - in which each processing level (each synapses) comes into play. The present review points to the visual thalamus, and likely other associated nonthalamic nuclei, as crucially involved in early emotional processing of visual stimulation. It is important to note that an initial evaluation in the ascending precortical path is also observed in other sensory modalities. Thus, gustatory and somatosensory inputs are also emotionally marked in the thalamus, and even earlier, at the sensory receptor level in both modalities and also in the case of olfactory inputs (for a review, see Kryklywy et al., 2020). The possibility that tonotopic first-order structures such as the cochlear nucleus may also rapidly discriminate emotional auditory stimuli has also been raised recently (rat: Paolini et al., 2020).

In the visual domain, the LGN seems to be a key IES, labeling sensory inputs as emotional at $20-40 \mathrm{~ms}$ from their onset, thanks to its contrasted capability to locally process relative complex stimuli, with the fast contribution of the TRN as a global evaluator of visual features. This information, labeled as emotional if pertinent, would reach the visual cortex around 60-70 ms after stimulus onset. In parallel, but some 10-20 ms later (i.e., 40-60 ms from stimulus onset), the SC-pulvinar tandem could also evaluate the ascending information. Whereas the SC-pulvinar tandem would probably not contribute to the initial V1 (or V2/V3) cortical response to emotional stimuli, its action would reinforce and complement the LGN-TRN evaluation in ascending phases. Later, the visual input already marked as emotional would follow the routes shown in Figure 4 towards the visual cortices and, through TRN and cortical interconnections, to other brain areas well known to be involved in emotional processing such as the amygdala, vPFC, and insula (e.g., K. H. Lee \& Siegle, 2009). Deep evaluation starts at this point, since emotional stimuli are more sophisticatedly processed in these structures. Information would also travel back from these structures to the LGN, TRN, and pulvinar, among other brain areas. The recurrent information interchange among these elements is also characteristic of deep evaluation, and often derives in subjective (e.g., fear feeling), autonomic (e.g., increased skin conductance), motor (e.g., orienting or avoidance), and cognitive changes (e.g., mnemonic actualization), as a continuation of the initial evaluation reviewed here, of fast and (rudimentary) perceptual nature.

Therefore, the present proposal does not contradict previous data on the evaluative capabilities of the amygdala, vPFC, insula, or other structures, which is backed by a solid background of concurrent and abundant data. However, their influence over visual cortices or other brain structures involved in visual processing would belong to deep evaluation rather than being the first markers of emotionality or IESs. Particularly, the role of the amygdala, which in current models of emotional processing is often proposed as the cornerstone of emotional processing - also in humans - should be discussed beyond the basic outlines mentioned in the Introduction. As indicated, initial evaluation, one of the main ingredients in this cornerstone role, seems not to be within the reach of the amygdala mainly for three reasons. First, because the multisynaptic path that visual information needs to reach this structure (four synapses minimum) causes latencies incompatible with observations. Focusing on faces, the stimuli evoking the faster amygdalar responses, latencies are longer than required for any IES. Thus, the face-sensitive neurons of the macaque amygdala (i.e., they specifically react to faces and not to other visual stimuli) respond from $60 \mathrm{~ms}$ (Nakamura et al., 1992), and typically from $100 \mathrm{~ms}$ or beyond (Leonard et al., 1985; Sanghera et al., 1979; S. Wang et al., 2014). In humans, results are parallel but with the known increase in latency (Pessoa \& Adolphs, 2010), and the earliest responses have been observed at $74 \mathrm{~ms}$, as indicated in the Introduction (Méndez-Bértolo et al., 2016), and beyond $250 \mathrm{~ms}$ in several studies (Krolak-Salmon et al., 2004; Mormann et al., 2008; Rutishauser et al., 2011).

The second reason for which the amygdala is likely not an IES is that it lacks the necessary cytoarchitecture. As mentioned in the Introduction, no amygdalar nuclei have been reported to incorporate focal processors in charge of specific receptive fields, which usually follow a retinotopic organization or, alternatively, to include global processors connected to focal ones in order to locally analyze visual features - shapes, motion patterns, colors, etc. - of the incoming stimulation, and hence to initially detect emotional stimuli. In other words, the amygdala is not a visual processing structure. Indeed, amygdalar neurons responding to faces, and probably other amygdalar neurons, do not respond exclusively to visual information, an important part of them also respond to auditory stimuli (Kuraoka \& Nakamura, 2007). The third reason is the relative specialization of the amygdala in face processing (for a meta-analysis, see Sergerie et al., 2008). While some amygdalar neurons specifically respond to other nonfacial significant stimuli, such as food or animals (irrespective of their emotional valence), their response latency is usually longer (e.g., $\sim 320 \mathrm{~ms}$ on average in the case of stimuli depicting animals; human: Mormann et al., 2011). Relatedly, Méndez-Bértolo et al. (human: 2016) showed that amygdalar differential activity between emotional and nonemotional stimuli is observed more than $100 \mathrm{~ms}$ later in response to nonfacial than to facial stimuli. Indeed, the amygdala is considered a key piece of the neural circuitry involved in social behavior (e.g., Amaral, 2003). However, and importantly, IESs should also be able to rapidly detect and label nonfacial visual events, whose impact on survival may be even more dramatic.

Alternatively, the amygdala is directly connected with effector brain areas in charge of motor responses (periaqueductal gray matter and striatum; Emery \& Amaral, 2000), vegetative (hypothalamus; LeDoux, 2000), subjective (e.g., fear feeling, in which the bed nucleus of the stria terminalis is involved; Walker et al., 2003) and cognitive changes (e.g., hippocampal complex [memory] and visual cortices [attention]; see Adolphs, 2004; Dolcos et al., 2004). Thanks to this pattern of interconnections, its main role would be to integrate sensory facial information 
with other associated information such as task demands, past experiences, reward value, or social context, and this integration would lead to a judgment about the emotion content of faces (X. D. Wang et al., 2014), a role that could be extended, later in time, to other visual stimuli. In sum, this multifaceted connectivity signals the amygdala as a deep evaluator of the visual input. A similar role could be proposed for the $\mathrm{vPFC}$, insula, or any other structure that receives direct inputs from visual cortices and connects, also directly, to effector systems (for a review on the connectivity of these structures, see Carretié et al., 2009). In humans, the vPFC and insula may even allow "greater resolution" in this integrative role as well as in the motor, subjective, and cognitive outputs they may organize due to their richer connectivity (e.g., the vPFC, but not the amygdala, is connected to motor cortices; Emery \& Amaral, 2000). Additionally, the three structures are involved in different forms of emotional memory such as Pavlovian conditioning, and in different sensorial modalities (e.g., in humans, amygdala: Knight et al., 2004; insula: MacNamara et al., 2015; vPFC: Ostlund \& Balleine, 2007). Since they send direct and/or indirect afferences to several IESs, including the sensory thalamus, they could mark those sensory patterns that associate with emotional stimuli to be locally stored in the IESs. For example, and in the auditory domain (more explored than the visual in this respect), inactivation of the basolateral amygdala prior to auditory fear conditioning prevents the auditory thalamus-which typically shows rapid enhanced responses to fear-conditioned auditory stimuli (10-50 ms) - from discriminating conditioned from unconditioned stimuli (rat: Maren et al., 2001).

As described before, three key prerequisites for an IES (short latency, visual feature processing architecture, nonspecific content detection) seem to be met by the LGN, which belongs to the main and fastest ascending route of visual information in humans. Data on its involvement in early emotional evaluation are scarce since the LGN has been usually out of the scope of research (i.e., it has hardly been a target in animal intracranial recordings, or a specific region of interest in human fMRi studies using visual emotional stimulation), but results from other lines of research provide some relevant clues. Regarding response latency, the LGN may modulate the visual input at $\sim 20$ to $40 \mathrm{~ms}$ from stimulus onset, as indicated. With respect to its capability to evaluate visual features, current data show that certain intrinsic characteristics of the stimulus, such as shape novelty (Ortuño et al., 2014), may modulate LGN responses, and we hypothesize that the idiosyncratic saliency of emotional stimulation may be among them. This modulation requires focal and global feature analysis to detect shapes, colors, motion, etc., that could identify an emotional stimulus (see Figure 2). The LGN is undoubtedly capable of developing the focal analysis of visual input through relay cells (P, M, and $\mathrm{K}$ ), and global analysis, interconnecting several relay cells to increase the visual area to be processed, could be carried out by the TRN. Importantly, the TRN is susceptible to long-term potentiation (Sieber et al., 2013), pointing to a capability to encode certain visual information and, ultimately, to compare online the incoming information with stored features corresponding to emotional stimuli. Participation of LGN interneurons - also interconnected to an important number and variety of relay cells - as a global processor is also probable in light of the reviewed data. Labelling the stimulus as emotional would likely consist of a burst firing of LGN relay cells shortly after stimulus onset since, according to the information reviewed in previous sections, this spike pattern marks relevant visual inputs and privileges them in subsequent visual cortex processing. Additionally, the TRN would distribute this information to other thalamic and cortical areas.

However, IESs likely consist of a network of complementary structures rather than a single node. Thus, whereas the LGNTRN tandem is proposed here as the core IES, other structures may take part in the initial, ascending evaluation of stimulation. The involvement of the pulvinar, in close association with the superior colliculus, in early emotional evaluation has also been reviewed. Two evidence points have been mentioned suggesting that the pulvinar is probably not the core of the IESs network. First, the main inputs to the visual pulvinar are descending projections from different visual cortices, and its main role is acting as a hub that coordinates cortico-cortical activity (Eradath et al., 2020; Jaramillo et al., 2019). Second, reported latencies of pulvinar-enhanced activity towards emotional stimulation seem, up to now, longer than required to explain initial visual cortex responses to emotional stimuli, as reviewed before. A third reason may be added here, of clinical nature in this case: lesions in the pulvinar do not seem to impair emotional recognition, at least using faces as stimuli (humans: Lucas et al., 2019). Whereas not a core IES, the involvement of the pulvinar (or the superior colliculus-pulvinar tandem) in the initial evaluation network is backed by experimental data and may complement the LGN-TRN previous evaluation. The fact that the pulvinar reaches some brain areas different from those innervated by the LGN-TRN tandem - and that it conveys complementary information (more related to motion, both regarding the stimulus and the eyes/body themselves) to that processed by the LGN (but also relevant to emotional processing) — would indeed be a valuable contribution to early evaluation. Nonthalamic first-order structures, such as the pretectum and nuclei belonging to the accessory optic system described in this review, can detect or evaluate certain aspects of the visual input as well, particularly those related to stimulus motion and motor behavior (e.g., eye pursuit) that are important parameters regarding many emotional visual events. Therefore, the different nodes of the IESs network, although directly and indirectly interconnected and capable of serially influencing each other, largely act in parallel following a sort of "multiple waves" design (Pessoa \& Adolphs, 2010).

In conclusion, current data clearly show that a key missing link exists in emotional processing, which consists in defining the cerebral structures forming the initial evaluation system. While this gap seems evident, the candidates to be an IES are still to be experimentally explored. Our proposal on the key involvement of the LGN-TRN in this initial, ascending evaluation, with the later contribution of the superior colliculus-pulvinar, is based on the existing literature, but we are conscious that this is still scarce and that further research is needed to confirm (or discard) it. In any case, the information reviewed here points to the importance of broadening the focus of affective neuroscience to include the 
thalamus as a field of research, as cognitive neuroscience has begun to do in recent years. Two lines of research appear of special interest. On one hand, employing emotional stimuli in intracranial recordings of LGN (both relay and interneuron) and TRN cells of primates. On the other hand, designing fMRI studies in human subjects, also employing emotional stimulation, including the LGN as a target region. The susceptibility of the TRN and other visual thalamic nuclei to long-term potentiation is also a scarcely explored, but crucial, issue. Indeed, stimulus evaluation necessarily requires the storage of certain visual patterns that allow the identification of upcoming emotional events. In sum, it seems worth rescuing at least part of the prominence the thalamus had in the first years of affective neuroscience.

\section{Declaration of Conflicting Interests}

The author(s) declared no potential conflicts of interest with respect to the research, authorship, and/or publication of this article.

\section{Funding}

The author(s) disclosed receipt of the following financial support for the research, authorship, and/or publication of this article: This research was supported by the Ministerio de Ciencia e Innovación (MICINN) (Grant no. PGC2018-093570B-I00) and the Comunidad de Madrid (Grant no. HUM19-HUM5705).

\section{ORCID iD}

Luis Carretié iD https://orcid.org/0000-0001-7375-6739

\section{Note}

1 A retinotopical organization refers to a distribution of brain neurons in certain areas where the spatial organization of the retina is relatively preserved. Thus, for example, adjacent neurons of these retinotopic regions process adjacent portions of the visual field.

\section{References}

Acunzo, D., MacKenzie, G., \& van Rossum, Mark, C. W. (2019). Spatial attention affects the early processing of neutral versus fearful faces when they are task-irrelevant: A classifier study of the EEG C1 component. Cognitive, Affective, \& Behavioral Neuroscience, 19, 123-137.

Adolphs, R. (2004). Emotional vision. Nature Neuroscience, 7, 1167-1168.

Adolphs, R. (2008). Fear, faces, and the human amygdala. Current Opinion in Neurobiology, 18, 166-172.

Adolphs, R., Kawasaki, H., Oya, H., \& Howard, M. A. (2006). Intracranial electrophysiology of the human orbitofrontal cortex. In D. H. Zald \& S. L. Rauch (Eds.), The orbitofrontal cortex (pp. 355-375). Oxford University Press.

Ajina, S., \& Bridge, H. (2018). Blindsight relies on a functional connection between hMT and the lateral geniculate nucleus, not the pulvinar. PLoS Biology, 16, Article e2005769.

Ales, J. M., Yates, J. L., \& Norcia, A. M. (2010). V1 is not uniquely identified by polarity reversals of responses to upper and lower visual field stimuli. NeuroImage, 52, 1401-1409.

Alitto, H., Rathbun, D. L., Vandeleest, J. J., Alexander, P. C., \& Usrey, W. M. (2019). The augmentation of retinogeniculate communication during thalamic burst mode. Journal of Neuroscience, 39, $5697-5710$.

Almeida, I., Soares, S. C., \& Castelo-Branco, M. (2015). Correction: The distinct role of the amygdala, superior colliculus and pulvinar in processing of central and peripheral snakes. PLoS One, 10, Article e0141175.

Amaral, D. G. (2003). The amygdala, social behavior, and danger detection. Annals of the New York Academy of Sciences, 1000, 337-347.

Anders, S., Lotze, M., Erb, M., Grodd, W., \& Birbaumer, N. (2004). Brain activity underlying emotional valence and arousal: A response-related fMRI study. Human Brain Mapping, 23, 200-209.

Arcaro, M. J., Pinsk, M. A., \& Kastner, S. (2015). The anatomical and functional organization of the human visual pulvinar. Journal of Neuroscience, 35, 9848-9871.

Baldwin, M. K., Balaram, P., \& Kaas, J. H. (2017). The evolution and functions of nuclei of the visual pulvinar in primates. Journal of Comparative Neurology, 525, 3207-3226.

Basso, M. A., \& May, P. J. (2017). Circuits for action and cognition: A view from the superior colliculus. Annual Review of Vision Science, 3, 197-226.

Bender, D. B. (1982). Receptive-field properties of neurons in the macaque inferior pulvinar. Journal of Neurophysiology, 48, 1-17.

Berman, R. A., \& Wurtz, R. H. (2010). Functional identification of a pulvinar path from superior colliculus to cortical area MT. Journal of Neuroscience, 30, 6342-6354.

Blitz, D. M., \& Regehr, W. G. (2005). Timing and specificity of feed-forward inhibition within the LGN. Neuron, 45, 917-928.

Bragg, E. M., Fairless, E. A., Liu, S., \& Briggs, F. (2017). Morphology of visual sector thalamic reticular neurons in the macaque monkey suggests retinotopically specialized, parallel stream-mixed input to the lateral geniculate nucleus. Journal of Comparative Neurology, 525, 1273-1290.

Bridge, H., Leopold, D. A., \& Bourne, J. A. (2016). Adaptive pulvinar circuitry supports visual cognition. Trends in Cognitive Sciences, 20 , 146-157.

Britton, J. C., Phan, K. L., Taylor, S. F., Welsh, R. C., Berridge, K. C., \& Liberzon, I. (2006). Neural correlates of social and nonsocial emotions: An fMRI study. NeuroImage, 31, 397-409.

Broca, P. (1878). Anatomie comparée des circonvolutions cérébrales. Le grand lobe limbique et la scissure limbique dans la série des mammifères. Revue d'Anthropologie, 1, 385-498.

Brosch, T., Pourtois, G., \& Sander, D. (2010). The perception and categorisation of emotional stimuli: A review. Cognition \& Emotion, 24, 377-400.

Brown, M. R., Lebel, R. M., Dolcos, F., Wilman, A. H., Silverstone, P. H., Pazderka, H., Fujiwara, E., Wild, C., Carroll, A. M., Hodlevskyy, O., Zedkova, L., Zwaigenbaum, L., Thompson, A. H., Greensaw, A. J., \& Dursun, S. M. (2012). Effects of emotional context on impulse control. NeuroImage, 63, 434- 446.

Bühler, M., Vollstädt-Klein, S., Klemen, J., \& Smolka, M. N. (2008). Does erotic stimulus presentation design affect brain activation patterns? Event-related vs. blocked fMRI designs. Behavioral and Brain Functions, 4(1), Article 30.

Büttner-Ennever, J., Cohen, B., Horn, A., \& Reisine, H. (1996). Efferent pathways of the nucleus of the optic tract in monkey and their role in eye movements. Journal of Comparative Neurology, 373, 90-107.

Cannon, W. B. (1927). The James-Lange theory of emotions: A critical examination and an alternative theory. The American Journal of Psychology, 39, 106-124.

Capilla, A., Melcón, M., Kessel, D., Calderón, R., Pazo-Álvarez, P., \& Carretié, L. (2016). Retinotopic mapping of visual event-related potentials. Biological Psychology, 118, 114-125.

Carretié, L. (2014). Exogenous (automatic) attention to emotional stimuli: A review. Cognitive, Affective and Behavioral Neuroscience, 14, 1228-1258.

Carretié, L., Albert, J., López-Martín, S., \& Tapia, M. (2009). Negative brain: An integrative review on the neural processes activated by unpleasant stimuli. International Journal of Psychophysiology, 71, 57-63.

Casagrande, V. A., Royal, D. W., \& Sáry, G. (2005). Extraretinal inputs and feedback mechanisms to the lateral geniculate nucleus (LGN). In J. Kremers (Ed.), The primate visual system: A comparative approach (pp. 191-211). Wiley Online Library. 
Cerkevich, C. M., Lyon, D. C., Balaram, P., \& Kaas, J. H. (2014). Distribution of cortical neurons projecting to the superior colliculus in macaque monkeys. Eye and Brain, 2014, 121-137.

Cola, M. G., Gray, D. N., Seltzer, B., \& Cusick, C. G. (1999). Human thalamus: Neurochemical mapping of inferior pulvinar complex. NeuroReport, 10, 3733-3738.

Costafreda, S. G., Brammer, M. J., David, A. S., \& Fu, C. H. Y. (2008). Predictors of amygdala activation during the processing of emotional stimuli: A meta-analysis of 385 PET and fMRI studies. Brain Research Reviews, 58, 57-70.

Critchley, H., Daly, E., Phillips, M., Brammer, M., Bullmore, E., Williams, S., van Amelsvoort, T., Robertson, D., David, A., \& Murphy, D. (2000). Explicit and implicit neural mechanisms for processing of social information from facial expressions: A functional magnetic resonance imaging study. Human Brain Mapping, 9, 93-105.

Daley, R. T., Bowen, H. J., Fields, E. C., Parisi, K. R., Gutchess, A., \& Kensinger, E. A. (2020). Neural mechanisms supporting emotional and selfreferential information processing and encoding in older and younger adults. Social Cognitive and Affective Neuroscience, 15, 405-421.

Damasio, A. (1994). Descartes' error: Emotion, reason, and the human brain. Putnam.

Das, P., Kemp, A. H., Liddell, B. J., Brown, K. J., Olivieri, G., Peduto, A., Gordon, E., \& Williams, L. M. (2005). Pathways for fear perception: Modulation of amygdala activity by thalamo-cortical systems. NeuroImage, 26, 141-148.

Debanne, D. (2004). Information processing in the axon. Nature Reviews Neuroscience, 5(4), 304-316.

De Gelder, B., \& Hadjikhani, N. (2006). Non-conscious recognition of emotional body language. NeuroReport, 17, 583-586.

De Gelder, B., Snyder, J., Greve, D., Gerard, G., \& Hadjikhani, N. (2004). Fear fosters flight: A mechanism for fear contagion when perceiving emotion expressed by a whole body. Proceedings of the National Academy of Sciences of the USA, 101, 16701-16706.

Derrington, A., \& Lennie, P. (1984). Spatial and temporal contrast sensitivities of neurones in lateral geniculate nucleus of macaque. The Journal of Physiology, 357, 219-240.

DeYoe, E. A., \& van Essen, D. C. (1988). Concurrent processing streams in monkey visual cortex. Trends in Neurosciences, 11, 219-226.

Di Russo, F., Martinez, A., \& Hillyard, S. A. (2003). Source analysis of event-related cortical activity during visuo-spatial attention. Cerebral Cortex, 13, 486-499.

Dolcos, F., LaBar, K. S., \& Cabeza, R. (2004). Interaction between the amygdala and the medial temporal lobe memory system predicts better memory for emotional events. Neuron, 42, 855-863.

Domes, G., Schulze, L., Böttger, M., Grossmann, A., Hauenstein, K., Wirtz, P. H., Heinrichs, M., \& Herpertz, S. C. (2010). The neural correlates of sex differences in emotional reactivity and emotion regulation. Human Brain Mapping, 31, 758-769.

Duan, X., Dai, Q., Gong, Q., \& Chen, H. (2010). Neural mechanism of unconscious perception of surprised facial expression. NeuroImage, 52, 401-407.

Dunsmoor, J. E., Kubota, J. T., Li, J., Coelho, C. A., \& Phelps, E. A. (2016). Racial stereotypes impair flexibility of emotional learning. Social Cognitive and Affective Neuroscience, 11, 1363-1373.

Edmiston, E. K., McHugo, M., Dukic, M. S., Smith, S. D., Abou-Khalil, B., Eggers, E., \& Zald, D. H. (2013). Enhanced visual cortical activation for emotional stimuli is preserved in patients with unilateral amygdala resection. The Journal of Neuroscience, 33, 11023-11031.

Eldar, S., Yankelevitch, R., Lamy, D., \& Bar-Haim, Y. (2010). Enhanced neural reactivity and selective attention to threat in anxiety. Biological Psychology, 85, 252-257.

Emery, N. J., \& Amaral, D. G. (2000). The role of the amygdala in primate social cognition. In R. D. Lane \& L. Nadel (Eds.), Cognitive neuroscience of emotion (pp. 156-191). Oxford University Press.
Eradath, M. K., Pinsk, M. A., \& Kastner, S. (2020). A causal role for pulvinar in coordinating task independent corticocortical interactions. BioRXiv. https://doi.org/10.1101/2020.03.07.982215

Fichtenholtz, H. M., Dean, H. L., Dillon, D. G., Yamasaki, H., McCarthy, G., \& LaBar, K. S. (2004). Emotion-attention network interactions during a visual oddball task. Cognitive Brain Research, 20, 67-80.

Frank, D. W., \& Sabatinelli, D. (2014). Human thalamic and amygdala modulation in emotional scene perception. Brain Research, 1587, 69-76.

Fredericks, C. A., Giolli, R. A., Blanks, R. H. I., \& Sadun, A. A. (1988). The human accessory optic system. Brain Research, 454, 116-122.

Gamlin, P. D. R. (2006). The pretectum: Connections and oculomotorrelated roles. Progress in Brain Research, 151, 379-405.

Garrett, A. S., \& Maddock, R. J. (2006). Separating subjective emotion from the perception of emotion-inducing stimuli: An fMRI study. Neurolmage, 33, 263-274.

Gattass, R., Soares, J. G., \& Lima, B. (2018). The pulvinar thalamic nucleus of non-human primates: Architectonic and functional subdivisions. Springer.

George, M. S., Ketter, T. A., Parekh, P. I., Horwitz, B., Herscovitch, P., \& Post, R. M. (1995). Brain activity during transient sadness and happiness in healthy women. American Journal of Psychiatry, 152, 341-351.

Ghodrati, M., Khaligh-Razavi, S., \& Lehky, S. R. (2017). Towards building a more complex view of the lateral geniculate nucleus: Recent advances in understanding its role. Progress in Neurobiology, 156, 214-255.

Giolli, R. A., Blanks, R. H. I., \& Lui, F. (2006). The accessory optic system: Basic organization with an update on connectivity, neurochemistry, and function. Progress in Brain Research, 151, 407-440.

Goldin, P. R., Hutcherson, C. A., Ochsner, K. N., Glover, G. H., Gabrieli, J. D., \& Gross, J. J. (2005). The neural bases of amusement and sadness: A comparison of block contrast and subject-specific emotion intensity regression approaches. NeuroImage, 1, 26-36.

Goldin, P. R., McRae, K., Ramel, W., \& Gross, J. J. (2008). The neural bases of emotion regulation: Reappraisal and suppression of negative emotion. Biological Psychiatry, 63, 577-586.

Govindaiah, G., \& Cox, C. L. (2006). Metabotropic glutamate receptors differentially regulate GABAergic inhibition in thalamus. Journal of Neuroscience, 26, 13443-13453.

Griggs, W. S., Amita, H., Gopal, A., \& Hikosaka, O. (2018). Visual neurons in the superior colliculus discriminate many objects by their historical values. Frontiers in Neuroscience, 12, Article 396.

Grosbras, M., \& Paus, T. (2006). Brain networks involved in viewing angry hands or faces. Cerebral Cortex, 16, 1087-1096.

Grünert, U., \& Martin, P. R. (2020). Cell types and cell circuits in human and non-human primate retina. Progress in Retinal and Eye Research, 78, Article 100844.

Guido, W., \& Weyand, T. (1995). Burst responses in thalamic relay cells of the awake behaving cat. Journal of Neurophysiology, 74, 1782-1786.

Guillery, R., \& Harting, J. K. (2003). Structure and connections of the thalamic reticular nucleus: Advancing views over half a century. Journal of Comparative Neurology, 463, 360-371.

Guillory, S. A., \& Bujarski, K. A. (2014). Exploring emotions using invasive methods: Review of 60 years of human intracranial electrophysiology. Social Cognitive and Affective Neuroscience, 9, 1880-1889.

Günther, V., Zimmer, J., Kersting, A., Hoffmann, K., Lobsien, D., \& Suslow, T. (2017). Automatic processing of emotional facial expressions as a function of social anhedonia. Psychiatry Research: Neuroimaging, $270,46-53$.

Hakamata, Y., Sato, E., Komi, S., Moriguchi, Y., Izawa, S., Murayama, N., Hanakawa, T., Inoue, Y., \& Tagaya, H. (2016). The functional activity and effective connectivity of pulvinar are modulated by individual differences in threat-related attentional bias. Scientific Reports, 6, Article 34777.

Halassa, M. M., \& Kastner, S. (2017). Thalamic functions in distributed cognitive control. Nature Neuroscience, 20, 1669-1679. 
Head, H. (1920). Studies in neurology, in two volumes. Hodder \& Stoughton. Hermann, A., Schäfer, A., Walter, B., Stark, R., Vaitl, D., \& Schienle, A. (2007). Diminished medial prefrontal cortex activity in blood-injection-injury phobia. Biological Psychology, 75, 124-130.

Hirsch, J. A., Wang, X., Sommer, F. T., \& Martinez, L. M. (2015). How inhibitory circuits in the thalamus serve vision. Annual Review of Neuroscience, 38, 309-329.

Holtmann, J., Herbort, M. C., Wüstenberg, T., Soch, J., Richter, S., Walter, H., Roepke, S., \& Schott, B. H. (2013). Trait anxiety modulates frontolimbic processing of emotional interference in borderline personality disorder. Frontiers in Human Neuroscience, 7, Article 54.

Horowitz, A., Barazany, D., Tavor, I., Bernstein, M., Yovel, G., \& Assaf, Y. (2015). In vivo correlation between axon diameter and conduction velocity in the human brain. Brain Structure and Function, 220, 1777-1788.

Huo, B., Zeater, N., Lin, M. K., Takahashi, Y. S., Hanada, M., Nagashima, J., Lee, B. C., Hata, J., Zaheer, A., Grünert, U., Miller, M. I., Rosa, M. G. P., Okano, H., Martin, P. R., \& Mitra, P. P. (2019). Relation of koniocellular layers of dorsal lateral geniculate to inferior pulvinar nuclei in common marmosets. European Journal of Neuroscience, 50, 4004-4017.

Ishii, T., \& Hosoya, T. (2020). Interspike intervals within retinal spike bursts combinatorially encode multiple stimulus features. BioRXiv. https://doi.org/10.1101/2020.02.13.947283

Jaramillo, J., Mejias, J. F., \& Wang, X. (2019). Engagement of pulvinocortical feedforward and feedback pathways in cognitive computations. Neuron, 101, 321-336.

Kang, D., Liu, Y., Miskovic, V., Keil, A., \& Ding, M. (2016). Large-scale functional brain connectivity during emotional engagement as revealed by beta-series correlation analysis. Psychophysiology, 53, 1627-1638.

Karama, S., Armony, J., \& Beauregard, M. (2011). Film excerpts shown to specifically elicit various affects lead to overlapping activation foci in a large set of symmetrical brain regions in males. PLoS One, 6(7), Article e22343.

Kehoe, E. G., Toomey, J. M., Balsters, J. H., \& Bokde, A. L. (2012). Personality modulates the effects of emotional arousal and valence on brain activation. Social Cognitive and Affective Neuroscience, 7, 858-870.

Kim, J., Shinkareva, S. V., \& Wedell, D. H. (2017). Representations of modality-general valence for videos and music derived from fMRI data. Neurolmage, 148, 42-54.

Kimura, A. (2014). Diverse subthreshold cross-modal sensory interactions in the thalamic reticular nucleus: Implications for new pathways of cross-modal attentional gating function. European Journal of Neuroscience, 39, 1405-1418.

Kimura, A. (2017). Robust interactions between the effects of auditory and cutaneous electrical stimulations on cell activities in the thalamic reticular nucleus. Brain Research, 1661, 49-66.

Kinoshita, M., Kato, R., Isa, K., Kobayashi, K., Kobayashi, K., Onoe, H., \& Isa, T. (2019). Dissecting the circuit for blindsight to reveal the critical role of pulvinar and superior colliculus. Nature Communications, 10 , Article 135.

Knight, D. C., Smith, C. N., Cheng, D. T., Stein, E. A., \& Helmstetter, F. J. (2004). Amygdala and hippocampal activity during acquisition and extinction of human fear conditioning. Cognitive, Affective, \& Behavioral Neuroscience, 4, 317-325.

Krauzlis, R. J., Lovejoy, L. P., \& Zénon, A. (2013). Superior colliculus and visual spatial attention. Annual Review of Neuroscience, 36 , $165-182$.

Krolak-Salmon, P., Hénaff, M., Tallon-Baudry, C., Yvert, B., Guénot, M., Vighetto, A., Mauguière, F., \& Bertrand, O. (2003). Human lateral geniculate nucleus and visual cortex respond to screen flicker. Annals of Neurology, 53, 73-80.

Krolak-Salmon, P., Hénaff, M., Vighetto, A., Bertrand, O., \& Mauguière, F. (2004). Early amygdala reaction to fear spreading in occipital, temporal, and frontal cortex: A depth electrode ERP study in human. Neuron, 42, 665-676.

Kryklywy, J. H., Ehlers, M. R., Anderson, A. K., \& Todd, R. M. (2020). From architecture to evolution: Multisensory evidence of decentralized emotion. Trends in Cognitive Sciences, 24, 916-929.

Kuraoka, K., \& Nakamura, K. (2007). Responses of single neurons in monkey amygdala to facial and vocal emotions. Journal of Neurophysiology, 97, 1379-1387.

Lane, R. D., Reiman, E. M., Ahern, G. L., Schwartz, G. E., \& Davidson, R. J. (1997). Neuroanatomical correlates of happiness, sadness, and disgust. The American Journal of Psychiatry, 154, 926-933.

Lane, R. D., Reiman, E. M., Bradley, M. M., Lang, P. J., Ahern, G. L., Davidson, R. J., \& Schwartz, G. E. (1997). Neuroanatomical correlates of pleasant and unpleasant emotion. Neuropsychologia, 35, 1437-1444.

Lashley, K. S. (1938). The thalamus and emotion. Psychological Review, $45,42-61$.

LeDoux, J. E. (1992). The emotional brain. Simon \& Schuster.

LeDoux, J. E. (2000). Emotion circuits in the brain. Annual Review of Neuroscience, 23, 155-184.

Lee, K. H., \& Siegle, G. J. (2009). Common and distinct brain networks underlying explicit emotional evaluation: A meta-analytic study. Social Cognitive and Affective Neuroscience, 7, 521-534.

Lee, T. M. C., Liu, H. L., Chan, C. C. H., Fang, S. Y., \& Gao, J. H. (2005). Neural activities associated with emotion recognition observed in men and women. Molecular Psychiatry, 10, 450-455.

Leonard, C., Rolls, E., Wilson, F., \& Baylis, G. (1985). Neurons in the amygdala of the monkey with responses selective for faces. Behavioural Brain Research, 15, 159-176.

Lesica, N. A., \& Stanley, G. B. (2004). Encoding of natural scene movies by tonic and burst spikes in the lateral geniculate nucleus. Journal of Neuroscience, 24, 10731-10740.

Levar, N., van Leeuwen, J. M., Denys, D., \& van Wingen, G. A. (2017). Divergent influences of anterior cingulate cortex GABA concentrations on the emotion circuitry. NeuroImage, 158, 136-144.

Liberzon, I., Taylor, S. F., Fig, L. M., Decker, L. R., Koeppe, R. A., \& Minoshima, S. (2000). Limbic activation and psychophysiologic responses to aversive visual stimuli: Interaction with cognitive task. Neuropsychopharmacology, 23, 508-516.

Lichev, V., Sacher, J., Ihme, K., Rosenberg, N., Quirin, M., Lepsien, J., Pampel, A., Rufer, M., Grabe, H.-J., Kugel, H., Kersting, A., Villringer, A., Lane, R. D., \& Suslow, T. (2015). Automatic emotion processing as a function of trait emotional awareness: An fMRI study. Social Cognitive and Affective Neuroscience, 10, 680-689.

Liddell, B. J., Brown, K. J., Kemp, A. H., Barton, M. J., Das, P., Peduto, A., Gordon, E., \& Williams, L. M. (2005). A direct brainstem-amygdalacortical "alarm" system for subliminal signals of fear. NeuroImage, 24, 235-243.

Liewald, D., Miller, R., Logothetis, N., Wagner, H., \& Schüz, A. (2014). Distribution of axon diameters in cortical white matter: An electronmicroscopic study on three human brains and a macaque. Biological Cybernetics, 108, 541-557.

Lindner, K., Neubert, J., Pfannmöller, J., Lotze, M., Hamm, A. O., \& Wendt, J. (2015). Fear-potentiated startle processing in humans: Parallel fMRI and orbicularis EMG assessment during cue conditioning and extinction. International Journal of Psychophysiology, 98, 535-545.

Liu, T. Y., Chen, Y. S., Hsieh, J. C., \& Chen, L. F. (2015). Asymmetric engagement of amygdala and its gamma connectivity in early emotional face processing. PLoS One, 10(1), Article e0115677.

Livingstone, M. S., \& Hubel, D. H. (1981). Effects of sleep and arousal on the processing of visual information in the cat. Nature, 291, 554-561.

Lucas, N., Bourgeois, A., Carrera, E., Landis, T., \& Vuilleumier, P. (2019). Impaired visual search with paradoxically increased facilitation by emotional features after unilateral pulvinar damage. Cortex, 120, 223-239. 
Luo, Q., Holroyd, T., Jones, M., Hendler, T., \& Blair, J. (2007). Neural dynamics for facial threat processing as revealed by gamma band synchronization using MEG. NeuroImage, 34, 839-847.

MacLean, P. D. (1949). Psychosomatic disease and the "visceral brain"; recent developments bearing on the Papez theory of emotion. Psychosomatic Medicine, 11, 338-353.

MacNamara, A., Rabinak, C. A., Fitzgerald, D. A., Zhou, X. J., Shankman, S. A., Milad, M. R., \& Phan, K. L. (2015). Neural correlates of individual differences in fear learning. Behavioural Brain Research, 287, 34-41.

Maren, S., Yap, S. A., \& Goosens, K. A. (2001). The amygdala is essential for the development of neuronal plasticity in the medial geniculate nucleus during auditory fear conditioning in rats. Journal of Neuroscience, 21, Article RC135.

Marrocco, R. T., McClurkin, J. W., \& Alkire, M. T. (1996). The influence of the visual cortex on the spatiotemporal response properties of lateral geniculate nucleus cells. Brain Research, 737, 110-118.

Martin, P. R., \& Solomon, S. G. (2019). The koniocellular whiteboard. Journal of Comparative Neurology, 527, 505-507.

Maunsell, J. H., \& Newsome, W. T. (1987). Visual processing in monkey extrastriate cortex. Annual Review of Neuroscience, 10, 363-401.

McAlonan, K., \& Brown, V. J. (2002). The thalamic reticular nucleus: More than a sensory nucleus? Neuroscientist, $8,302-305$.

McAlonan, K., Cavanaugh, J., \& Wurtz, R. H. (2008). Guarding the gateway to cortex with attention in visual thalamus. Nature, 456, 391-394.

Méndez-Bértolo, C., Moratti, S., Toledano, R., Lopez-Sosa, F., MartínezAlvarez, R., Mah, Y. H., Vuilleumier, P., Gil-Nagel, A., \& Strange, B. (2016). A fast pathway for fear in human amygdala. Nature Neuroscience, 19, 1041-1049.

Mizuno-Matsumoto, Y., Hayashi, T., Okamoto, E., Miwa, D., Asakawa, T., Muramatsu, A., Kato, M., \& Murata, T. (2013). Human-related emotional stimuli can cause a hippocampal and thalamic over-response in people with unstable personalities. Journal of Behavioral and Brain Science, 3, 509-517.

Morgan, J. L., \& Lichtman, J. W. (2020). An individual interneuron participates in many kinds of inhibition and innervates much of the mouse visual thalamus. Neuron, 106, 468-481.

Mormann, F., Dubois, J., Kornblith, S., Milosavljevic, M., Cerf, M., Ison, M., Tsuchiya, N., Kraskov, A., Quian Quiroga, R., Adolphs, R., Fried, I., \& Koch, C. (2011). A category-specific response to animals in the right human amygdala. Nature Neuroscience, 14, 1247-1249.

Mormann, F., Kornblith, S., Quiroga, R. Q., Kraskov, A., Cerf, M., Fried, I., \& Koch, C. (2008). Latency and selectivity of single neurons indicate hierarchical processing in the human medial temporal lobe. Journal of Neuroscience, 28, 8865-8872.

Morris, J. S., Friston, K. J., Büchel, C., Frith, C. D., Young, A. W., Calder, A. J., \& Dolan, R. J. (1998). A neuromodulatory role for the human amygdala in processing emotional facial expressions. Brain: A Journal of Neurology, 121, 47-57.

Morris, J., Friston, K., \& Dolan, R. J. (1997). Neural responses to salient visual stimuli. Proceedings of the Royal Society B: Biological Sciences, 264, 769-775.

Mourão-Miranda, J., Volchan, E., Moll, J., de Oliveira-Souza, R., Oliveira, L., Bramati, I., Gattass, R., \& Pessoa, L. (2003). Contributions of stimulus valence and arousal to visual activation during emotional perception. Neurolmage, 20, 1955-1963.

Mundinano, I., Fox, D. M., Kwan, W. C., Vidaurre, D., Teo, L., HommanLudiye, J., Goodale, M. A., Leopold, D. A., \& Bourne, J. A. (2018). Transient visual pathway critical for normal development of primate grasping behavior. Proceedings of the National Academy of Sciences of the USA, 115, 1364-1369.

Nakamura, K., Mikami, A., \& Kubota, K. (1992). Activity of single neurons in the monkey amygdala during performance of a visual discrimination task. Journal of Neurophysiology, 67, 1447-1463.
Nguyen, M. N., Hori, E., Matsumoto, J., Tran, A. H., Ono, T., \& Nishijo, H. (2013). Neuronal responses to face-like stimuli in the monkey pulvinar. European Journal of Neuroscience, 37, 35-51.

Norman, G. J., Norris, C. J., Gollan, J., Ito, T. A., Hawkley, L. C., Larsen, J. T., Cacioppo, J. T., \& Berntson, G. G. (2011). Current emotion research in psychophysiology: The neurobiology of evaluative bivalence. Emotion Review, 3, 349-359.

Norris, C. J., Chen, E. E., Zhu, D. C., Small, S. L., \& Cacioppo, J. T. (2004). The interaction of social and emotional processes in the brain. Journal of Cognitive Neuroscience, 16, 1818-1829.

Nummenmaa, L., Hirvonen, J., Parkkola, R., \& Hietanen, J. K. (2008). Is emotional contagion special? An fMRI study on neural systems for affective and cognitive empathy. NeuroImage, 43, 571-580.

O'Connor, D. H., Fukui, M. M., Pinsk, M. A., \& Kastner, S. (2002). Attention modulates responses in the human lateral geniculate nucleus. Nature Neuroscience, 5, 1203-1209.

Ohman, A. (2002). Automaticity and the amygdala: Nonconscious responses to emotional faces. Current Directions in Psychological Science, 11, 62-66.

Ortuño, T., Grieve, K. L., Cao, R., Cudeiro, J., \& Rivadulla, C. (2014). Bursting thalamic responses in awake monkey contribute to visual detection and are modulated by corticofugal feedback. Frontiers in Behavioral Neuroscience, 8, Article 198.

Ostlund, S. B., \& Balleine, B. W. (2007). Orbitofrontal cortex mediates outcome encoding in Pavlovian but not instrumental conditioning. Journal of Neuroscience, 27, 4819-4825.

Padmala, S., Lim, S. L., \& Pessoa, L. (2010). Pulvinar and affective significance: Responses track moment-to-moment stimulus visibility. Frontiers in Human Neuroscience, 4, Article 64.

Paolini, A. G., Morgan, S. J., \& Kim, J. H. (2020). Auditory fear conditioning alters neural gain in the cochlear nucleus: A wireless neural recording study in freely behaving rats. Neuronal Signaling, 4(4), Article NS20200009.

Papez, J. W. (1937). A proposed mechanism of emotion. Archives of Neurology \& Psychiatry, 38, 725-743.

Paret, C., Kluetsch, R., Ruf, M., Demirakca, T., Kalisch, R., Schmahl, C., \& Ende, G. (2014). Transient and sustained BOLD signal time courses affect the detection of emotion-related brain activation in fMRI. NeuroImage, 103, 522-532.

Pessoa, L., \& Adolphs, R. (2010). Emotion processing and the amygdala: From a "low road" to "many roads" of evaluating biological significance. Nature Reviews Neuroscience, 11, 773-783.

Phillips, M. L., Young, A. W., Senior, C., Brammer, M., Andrew, C., Calder, A. J., Bullmore, E. T., Perrett, D. I., Rowland, D., Williams, S. C. R., Gray, J. A., \& David, A. S. (1997). A specific neural substrate for perceiving facial expressions of disgust. Nature, 389, 495-498.

Pichon, S., de Gelder, B., \& Grezes, J. (2008). Emotional modulation of visual and motor areas by dynamic body expressions of anger. Social Neuroscience, 3, 199-212.

Pizzagalli, D., Regard, M., \& Lehmann, D. (1999). Rapid emotional face processing in the human right and left brain hemispheres: An ERP study. NeuroReport, 10, 2691-2698.

Poltoratski, S., Maier, A., Newton, A. T., \& Tong, F. (2019). Figure-ground modulation in the human lateral geniculate nucleus is distinguishable from top-down attention. Current Biology, 29, 2051-2057.

Pourtois, G., Grandjean, D., Sander, D., \& Vuilleumier, P. (2004). Electrophysiological correlates of rapid spatial orienting towards fearful faces. Cerebral Cortex, 14, 619-633.

Rauss, K., Schwartz, S., \& Pourtois, G. (2011). Top-down effects on early visual processing in humans: A predictive coding framework. Neuroscience \& Biobehavioral Reviews, 35, 1237-1253.

Rea, M., Kullmann, S., Veit, R., Casile, A., Braun, C., Belardinelli, M. O., Birbaumer, N., \& Caria, A. (2011). Effects of aversive stimuli on prospective memory. An event-related fMRI study. PLoS One, 6(10), Article e26290. 
Rudebeck, P. H., \& Murray, E. A. (2014). The orbitofrontal oracle: Cortical mechanisms for the prediction and evaluation of specific behavioral outcomes. Neuron, 84(6), 1143-1156.

Rutishauser, U., Tudusciuc, O., Neumann, D., Mamelak, A. N., Heller, A. C., Ross, I. B., Philpott, L., Sutherling, W. W., \& Adolphs, R. (2011). Single-unit responses selective for whole faces in the human amygdala. Current Biology, 21, 1654-1660.

Saalmann, Y. B., \& Kastner, S. (2011). Cognitive and perceptual functions of the visual thalamus. Neuron, 71, 209-223.

Sambuco, N., Bradley, M. M., Herring, D. R., \& Lang, P. J. (2020). Common circuit or paradigm shift? The functional brain in emotional scene perception and emotional imagery. Psychophysiology, 57, Article e13522.

Sanghera, M., Rolls, E., \& Roper-Hall, A. (1979). Visual responses of neurons in the dorsolateral amygdala of the alert monkey. Experimental Neurology, 63, 610-626.

Scharpf, K. R., Wendt, J., Lotze, M., \& Hamm, A. O. (2010). The brain's relevance detection network operates independently of stimulus modality. Behavioural Brain Research, 210, 16-23.

Schiller, P. H., \& Malpeli, J. G. (1978). Functional specificity of lateral geniculate nucleus laminae of the rhesus monkey. Journal of Neurophysiology, 41, 788-797.

Schlochtermeier, L. H., Kuchinke, L., Pehrs, C., Urton, K., Kappelhoff, H., \& Jacobs, A. M. (2013). Emotional picture and word processing: An FMRI study on effects of stimulus complexity. PLoS One, 8, Article e55619.

Schmid, M. C. (2010). Blindsight depends on the lateral geniculate nucleus. Nature, 466, 373-377.

Sergerie, K., Chochol, C., \& Armony, J. L. (2008). The role of the amygdala in emotional processing: A quantitative meta-analysis of functional neuroimaging studies. Neuroscience \& Biobehavioral Reviews, $32,811-830$.

Shafer, A. T., Matveychuk, D., Penney, T., O’Hare, A. J., Stokes, J., \& Dolcos, F. (2012). Processing of emotional distraction is both automatic and modulated by attention: Evidence from an event-related fMRI investigation. Journal of Cognitive Neuroscience, 24, 1233-1252.

Sherman, S. M. (2001). Tonic and burst firing: Dual modes of thalamocortical relay. Trends in Neurosciences, 24, 122-126.

Sieber, A. R., Min, R., \& Nevian, T. (2013). Non-Hebbian long-term potentiation of inhibitory synapses in the thalamus. The Journal of Neuroscience: The Official Journal of the Society for Neuroscience, 33, 15675-15685.

Siman-Tov, T., Papo, D., Gadoth, N., Schonberg, T., Mendelsohn, A., Perry, D., \& Hendler, T. (2009). Mind your left: Spatial bias in subcortical fear processing. Journal of Cognitive Neuroscience, 21, 1782-1789.

Soares, S. C., Maior, R. S., Isbell, L. A., Tomaz, C., \& Nishijo, H. (2017). Fast detector/first responder: Interactions between the superior colliculus-pulvinar pathway and stimuli relevant to primates. Frontiers in Neuroscience, 11, Article 67.

Stark, R., Schienle, A., Girod, C., Walter, B., Kirsch, P., Blecker, C., Ott, U., Schäfer, A., Sammer, G., Zimmermann, M., \& Vaitl, D. (2005). Erotic and disgust-inducing pictures: Differences in the hemodynamic responses of the brain. Biological Psychology, 70, 19-29.

Stark, R., Schienle, A., Walter, B., Kirsch, P., Blecker, C., Ott, U., Schäfer, A., Sammer, G., Zimmermann, M., \& Vaitl, D. (2004). Hemodynamic effects of negative emotional pictures: A test-retest analysis. Neuropsychobiology, 50, 108-118.

Stark, R., Schienle, A., Walter, B., Kirsch, P., Sammer, G., Ott, U., Blecker, C., \& Vaitl, D. (2003). Hemodynamic responses to fear and disgustinducing pictures: An fMRI study. International Journal of Psychophysiology, 50, 225-234.

Stolarova, M., Keil, A., \& Moratti, S. (2006). Modulation of the C1 visual event-related component by conditioned stimuli: Evidence for sensory plasticity in early affective perception. Cerebral Cortex, 16, 876-887.

Straube, T., Preissler, S., Lipka, J., Hewig, J., Mentzel, H. J., \& Miltner, W. H. (2010). Neural representation of anxiety and personality during exposure to anxiety-provoking and neutral scenes from scary movies. Human Brain Mapping, 31, 36-47.

Surguladze, S. A., Brammer, M. J., Young, A. W., Andrew, C., Travis, M. J., Williams, S. C., \& Phillips, M. L. (2003). A preferential increase in the extrastriate response to signals of danger. Neurolmage, 19, 1317-1328.

Suslow, T., Kugel, H., Reber, H., Bauer, J., Dannlowski, U., Kersting, A., Arolt, V., Heindel, W, Ohrmann, P., \& Egloff, B. (2010). Automatic brain response to facial emotion as a function of implicitly and explicitly measured extraversion. Neuroscience, 167, 111-123.

Takahashi, H., Koeda, M., Oda, K., Matsuda, T., Matsushima, E., Matsuura, M., Asai, K., \& Okubo, Y. (2004). An fMRI study of differential neural response to affective pictures in schizophrenia. NeuroImage, 22, 1247-1254.

Usrey, W. M., \& Alitto, H. J. (2015). Visual functions of the thalamus. Annual Review of Vision Science, 1, 351-371.

Van den Stock, J., Tamietto, M., Sorger, B., Pichon, S., Grézes, J., \& de Gelder, B. (2011). Cortico-subcortical visual, somatosensory, and motor activations for perceiving dynamic whole-body emotional expressions with and without striate cortex (V1). Proceedings of the National Academy of Sciences of the USA, 108, 16188-16193.

Van Dillen, L. F., Heslenfeld, D. J., \& Koole, S. L. (2009). Tuning down the emotional brain: An fMRI study of the effects of cognitive load on the processing of affective images. Neurolmage, 45, 1212-1219.

Van Le, Q., Isbell, L. A., Matsumoto, J., Nguyen, M., Hori, E., Maior, R. S., Tomaz, C., Tran, A. H., Ono, T., \& Nishijo, H. (2013). Pulvinar neurons reveal neurobiological evidence of past selection for rapid detection of snakes. Proceedings of the National Academy of Sciences of the USA, 110, 19000-19005.

Walker, D. L., Toufexis, D. J., \& Davis, M. (2003). Role of the bed nucleus of the stria terminalis versus the amygdala in fear, stress, and anxiety. European Journal of Pharmacology, 463, 199-216.

Walter, M., Bermpohl, F., Mouras, H., Schiltz, K., Tempelmann, C., Rotte, M., Heinze, H. J., Bogerts, B., \& Northoff, G. (2008). Distinguishing specific sexual and general emotional effects in fMRI-Subcortical and cortical arousal during erotic picture viewing. Neurolmage, 40, 1482-1494.

Wang, S., Tudusciuc, O., Mamelak, A. N., Ross, I. B., Adolphs, R., \& Rutishauser, U. (2014). Neurons in the human amygdala selective for perceived emotion. Proceedings of the National Academy of Sciences of the USA, 111, E3110-E3119.

Wang, X. D., Chen, C., Zhang, D., \& Yao, H. (2014). Cumulative latency advance underlies fast visual processing in desynchronized brain state. Proceedings of the National Academy of Sciences of the USA, 111, 515-520.

Wang, Y. C., Bianciardi, M., Chanes, L., \& Satpute, A. B. (2020). Ultra high field fMRI of human superior colliculi activity during affective visual processing. Scientific Reports, 10, Article 1331.

Warner, C. E., Goldshmit, Y., \& Bourne, J. A. (2010). Retinal afferents synapse with relay cells targeting the middle temporal area in the pulvinar and lateral geniculate nuclei. Frontiers in Neuroanatomy, 4, Article 8.

Warner, C. E., Kwan, W. C., \& Bourne, J. A. (2012). The early maturation of visual cortical area MT is dependent on input from the retinorecipient medial portion of the inferior pulvinar. Journal of Neuroscience, 32, 17073-17085.

Waugh, C. E., Hamilton, J. P., \& Gotlib, I. H. (2010). The neural temporal dynamics of the intensity of emotional experience. NeuroImage, 49 , 1699-1707.

Wehrum, S., Klucken, T., Kagerer, S., Walter, B., Hermann, A., Vaitl, D., \& Stark, R. (2013). Gender commonalities and differences in the neural processing of visual sexual stimuli. The Journal of Sexual Medicine, $10,1328-1342$.

Weyand, T. G. (2016). The multifunctional lateral geniculate nucleus. Reviews in the Neurosciences, 27, 135-157.

White, B. J., Berg, D. J., Kan, J. Y., Marino, R. A., Itti, L., \& Munoz, D. P. (2017). Superior colliculus neurons encode a visual saliency map 
during free viewing of natural dynamic video. Nature Communications, $8,1-9$.

Willenbockel, V., Lepore, F., Nguyen, D. K., Bouthillier, A., \& Gosselin, F. (2012). Spatial frequency tuning during the conscious and non-conscious perception of emotional facial expressions - An intracranial ERP study. Frontiers in Psychology, 3, Article 237.

Williams, L. M., Phillips, M. L., Brammer, M. J., Skerrett, D., Lagopoulos, J., Rennie, C., Bahramali, H., Olivieri, G., David, A. S., Peduto, A., \& Gordon, E. (2001). Arousal dissociates amygdala and hippocampal fear responses: Evidence from simultaneous fMRI and skin conductance recording. NeuroImage, 14, 1070-1079.

Winston, J. S., Vuilleumier, P., \& Dolan, R. J. (2003). Effects of low-spatial frequency components of fearful faces on fusiform cortex activity. Current Biology, 13, 1824-1829.
Wright, P., He, G., Shapira, N. A., Goodman, W. K., \& Liu, Y. (2004). Disgust and the insula: fMRI responses to pictures of mutilation and contamination. NeuroReport, 15, 2347-2351.

Wurtz, R. H. (2009). Superior colliculus. In L. R. Squire (Ed.), Encyclopedia of neuroscience (pp. 627-634). Academic Press.

Zald, D. H. (2003). The human amygdala and the emotional evaluation of sensory stimuli. Brain Research Reviews, 41, 88-123.

Zeater, N., Buzás, P., Dreher, B., Grünert, U., \& Martin, P. R. (2019). Projections of three subcortical visual centers to marmoset lateral geniculate nucleus. Journal of Comparative Neurology, 527, 535-545.

Zhang, W., \& Lu, J. (2012). Time course of automatic emotion regulation during a facial go/nogo task. Biological Psychology, 89, 444-449.

Zhou, H., Schafer, R. J., \& Desimone, R. (2016). Pulvinar-cortex interactions in vision and attention. Neuron, 89, 209-220. 